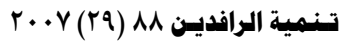

$$
\begin{aligned}
& \text { ص ص[1-1 [1-1] }
\end{aligned}
$$

$$
\begin{aligned}
& \text { أخلاقيات الجودة } \\
& \text { أخلاقيات المقارنة المرجعية أخيات } \\
& \text { أنموذجاً - مقاربات نظرية المرية } \\
& \text { الدكتور ميسر إبراهيم أحمد } \\
& \text { أستاذ مساعد - رئيس قسم الإدارة الصناعية } \\
& \text { كلية الإدارة و الاقتصاد - جامعة الموصل } \\
& \text { moyassar2001@yahoo.com }
\end{aligned}
$$

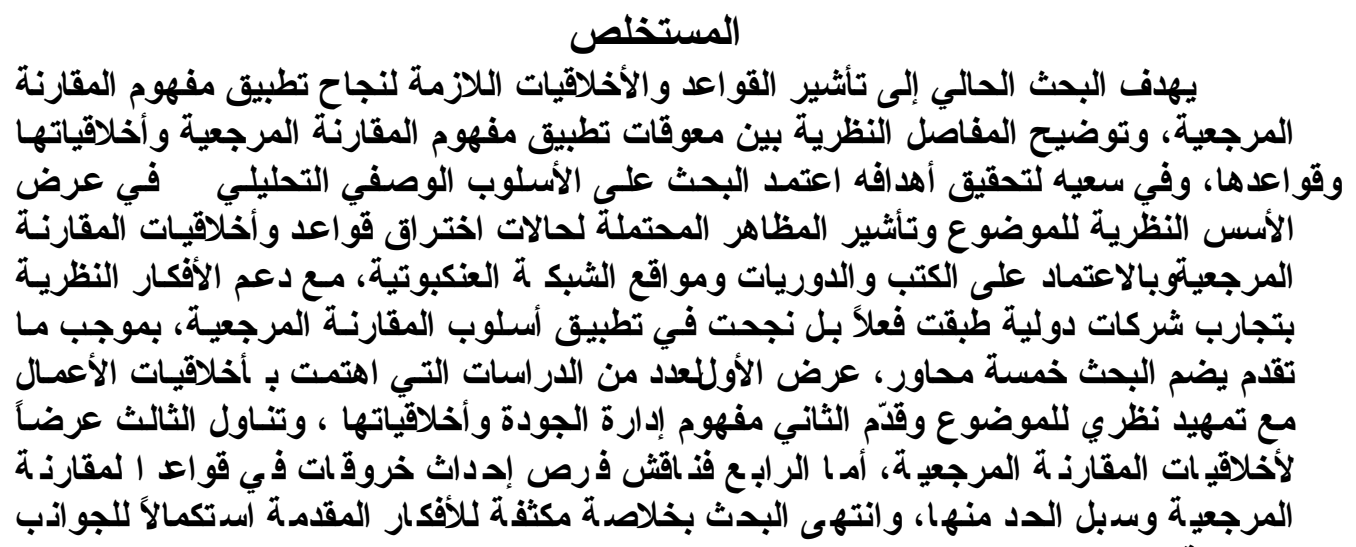

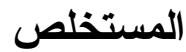

يهدف البحث الحالي إلى تأثير القواعد والأخلاقيات اللازمة لنجاح تطبيق مفهوم المقارنة

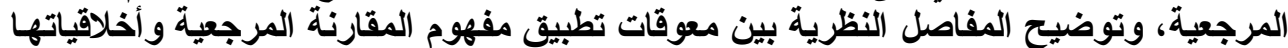

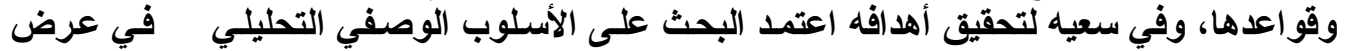

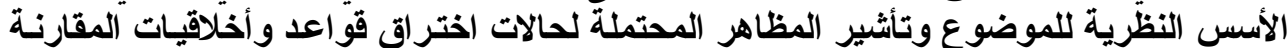

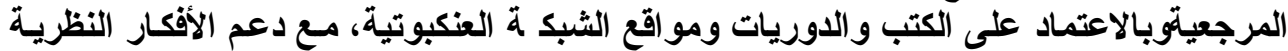

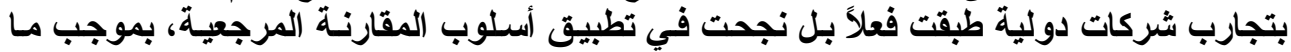

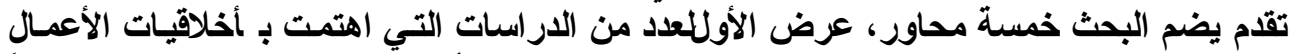

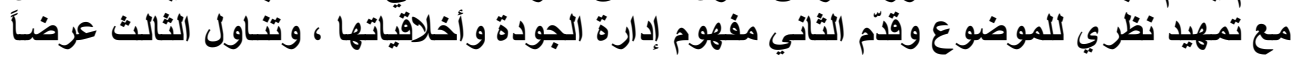

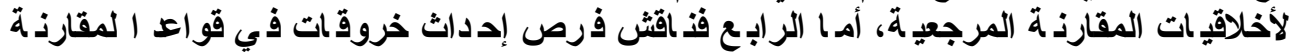

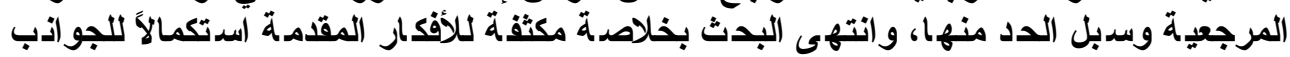

\title{
Quality Ethics - Benchmarking Ethics as a Model: Theoretical Approximations
}

\section{Moyassar I. Ahmed (PhD)}

Assistant Professor

Head of Industrial Management Department University of Mosul

\begin{abstract}
The current research aims at outlining the required principles and rules to succeed the application of the concept of benchmarking. It also explains the theoretical junctures among the hampers, ethics and rules of benchmarking. Achieving the targets, analytical description has been drawn to show the theoretical principles as well as seeing the probable phenomena of violating ethical standards. The study is expected to discuss five aspects; the first has
\end{abstract}

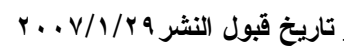

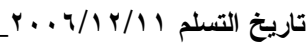


reviewed a literature on the concepts of ethical standards of businesses. The second has referred to the concepts and ethics of quality management as well. The third has showed however the quality ethics of benchmarking. Fourth has finally debated the opportunities of violations in the rules of benchmarking and the methods of limitations. The research then concluded into a gist of ideas to accomplish the analytical aspects.

\section{المقدمة}

تعدّ التحديات التقانية و المعلوماتية و الاقتصادية و القانونية الصفة الغالبة لبيئــة

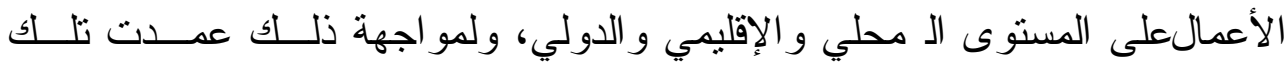

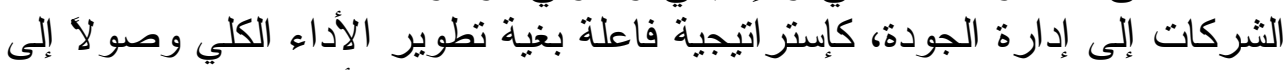

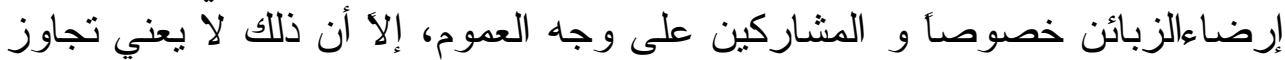

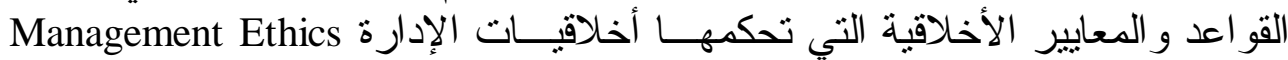

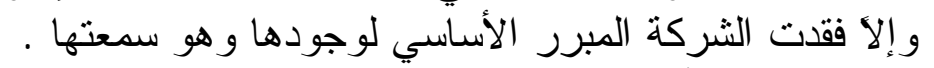

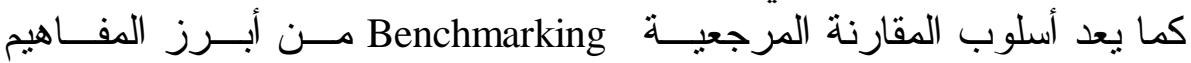

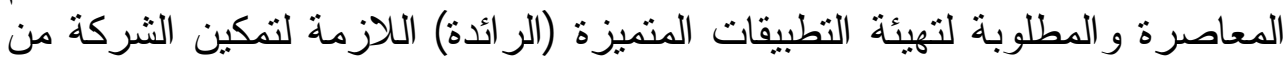

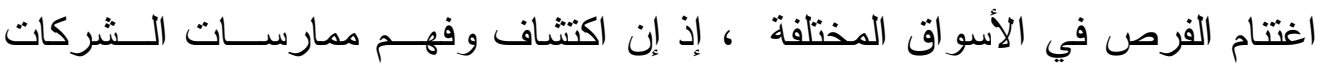

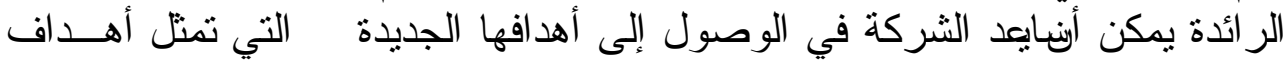
قد سبق للشركة الر ائدة تبنيها.

الإثار ات البحثية يعالج البحث موضو عه من خلال محاورة عدد من التساؤلات مثلت مستشكلة

$$
\begin{aligned}
& \text { بحثية جديرة بالتصدي و على النحو الآتي: } \\
& \text { ا ـ ما أخلاقيات إدارة الجودة؟ }
\end{aligned}
$$

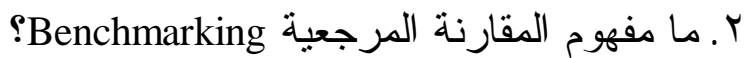
r. كيف بيكن اثتقاق أخلاقيات للمقارنة المرجية المعية؟ ع. هل تشكل أخلاقياتالمقارنة المرجعية معوقات لتطبية التبيق المفهوم أم هي أداة تخدم

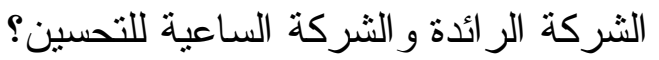

\section{الأهداف البحثية}

اختط البحث عدد آ من الأهداف سعياً لمعالجة تساؤلاته و اختبـــارَ لفروضـــهـ

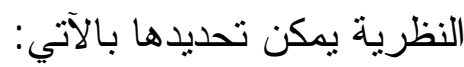

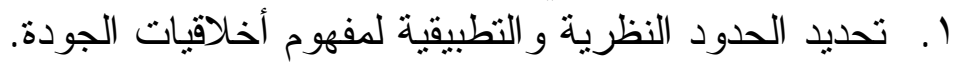

r. تأثير القو اعد و الأخلاقيات اللازمة لنجاح تطبيق مفهوم المقارنة المرجعية.

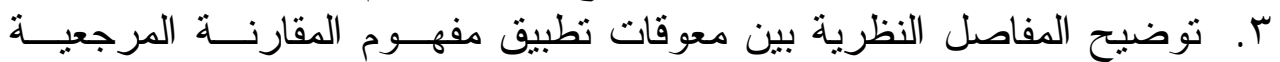

$$
\text { و أخلاقياتها وقو اعدها. }
$$

ع. تحديد وتحليل حالات تجاوز الخطوط الحمر اءو وآليات التصدي لها مــن قبـلـل

$$
\text { الشركة الر ائدة. }
$$

0. تقديم أفكار تعدّ دليلا للتو افق بين الثركة الساعية للتحسين و الثركة الر ائدة. 


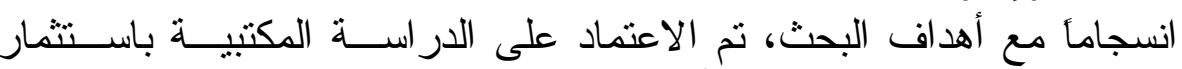

$$
\text { أسلوب البحث و إطاره }
$$

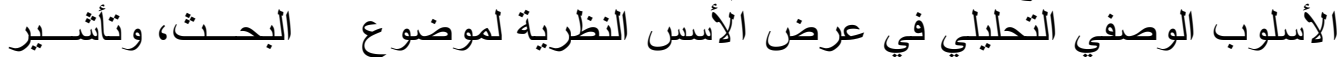

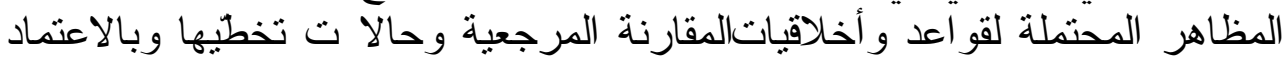

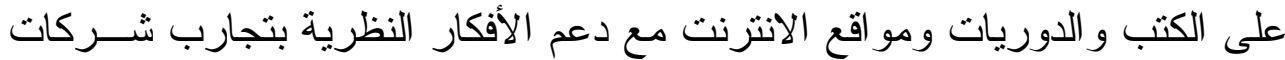
دولية طبقت فعلا بل نجحت في تطبيث أسلوب المقات المقارنة المرجعية. بموجب ما تقدم يضم البحث المحاور الآتية:

أو لا - قر اعة في در اسات سابقة مع تمهيد نظري عن أفرات الأخلاقيات. ثانياً - مفهوم إدارة إن الجودة و أخلاقياتها. ثالثأ - أخلاقيات المقوم المقارنة المرجعية. رابعاً - الفرص المتوقعة لإحداث خروقات في قو اعد المقارنة المرجعية وسبل الحد

\section{أولاً - قر اعة في دراسات سابقة مع تمهيد نظري عن الأخلاقيات}

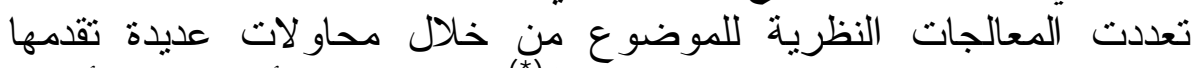
(Czarniawska- Jeerges \& Monthoux, 1968) ثم تبعه بعد ذلك عدد من المحاو لات من أهمها در اسة (De George,1987) بعنوان

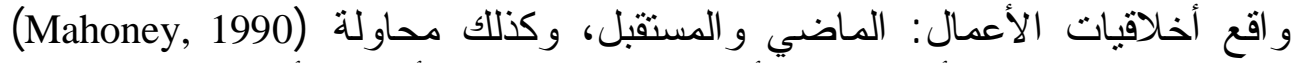

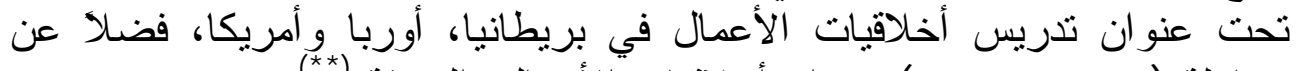

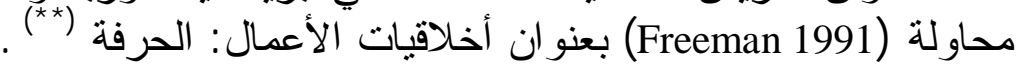

وفي منتصف التسعينات ظهرت محاولات أخرى، إذ إذ قدم (Shaw,1996)

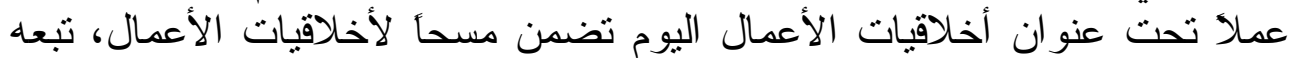
كل مــــــن (Cowton \& Crips, 1998) بعمل آخر حمل عنو ان أخلاقيات الأعمال مقدمات في النظرية و التطبيق . (Greenwood, 2000, 12)

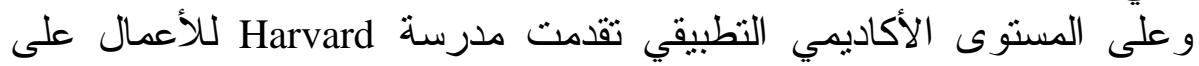

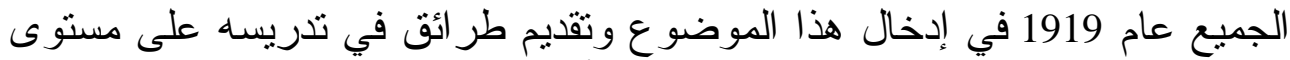

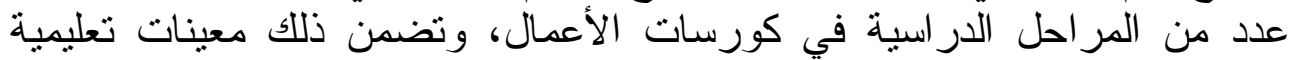
عديدة قدمت ملاحظات عن أساليب تدريس أخلاقيات الأعمال، واستتتجت أن

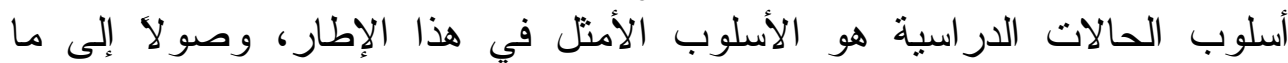

$$
\text { : (*) : (نظر في ذلك : (*) }
$$

- Greenwood ,Michelle R., (2000), "The Study of Business Ethics : A case For Dr Seuss ", A European Review, Vol.9, No.3 .

- Barkhuysen, Belinda , \& Rossouw , Gedeon J, (2000), " Business ethics as academic Field in Africa : its Current Status ", A European Review, Vol. 9 , No.4 . 


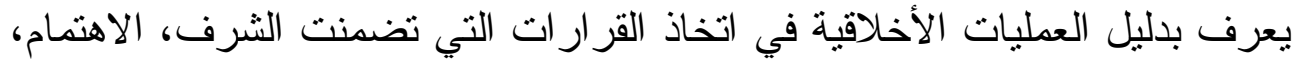

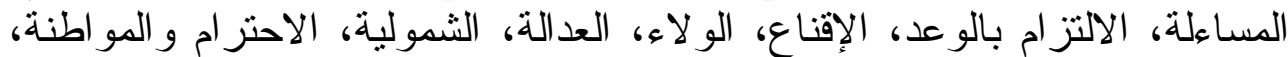

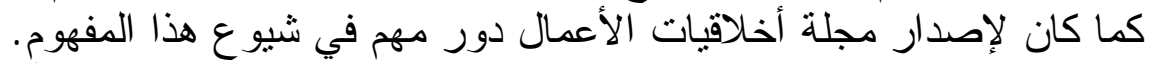

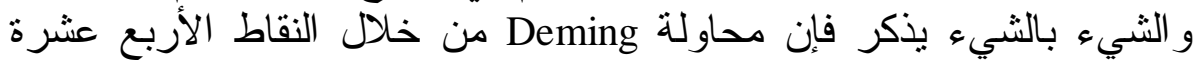

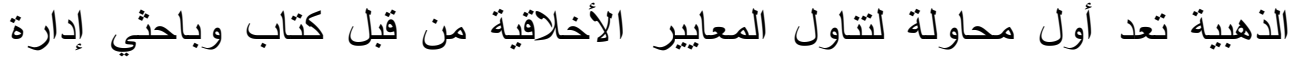

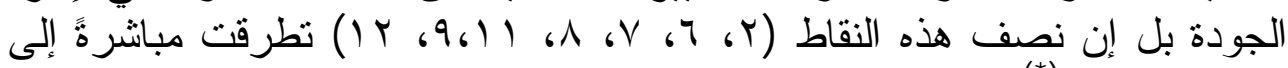
هذا الموضوع (*)

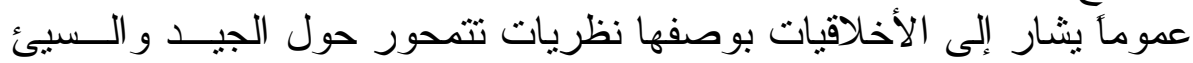

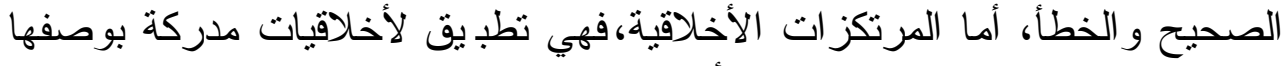

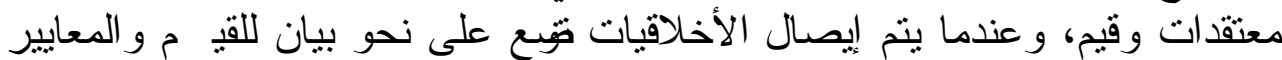

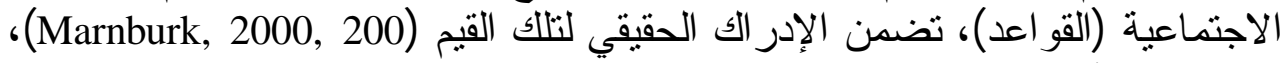

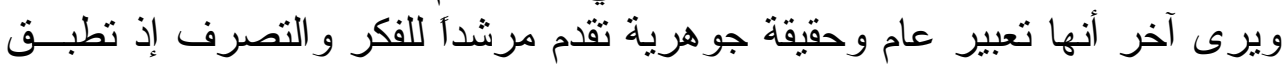

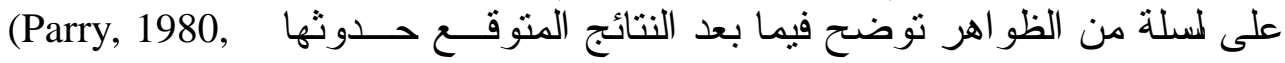

أما الاقتصاديون فينظرون إليها على أنها مجموعة الأبعاد الأخلاقية للأنشطة

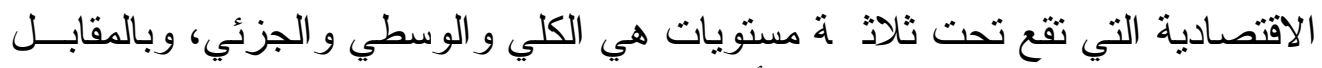

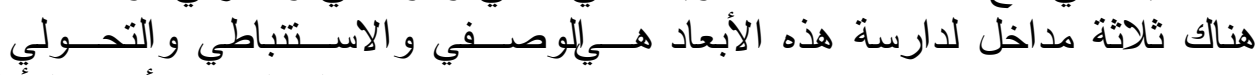

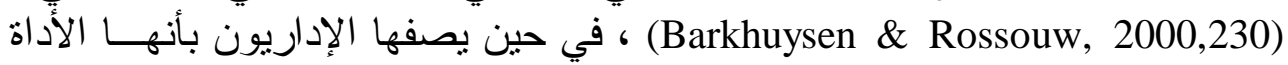

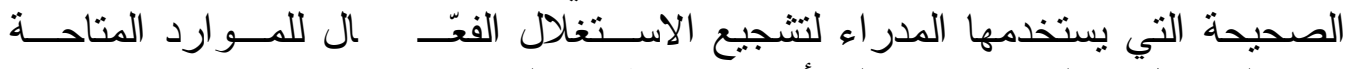

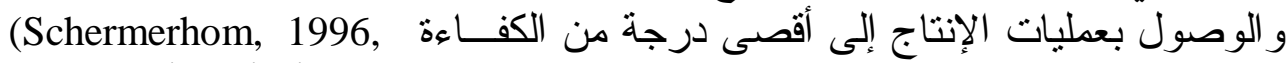

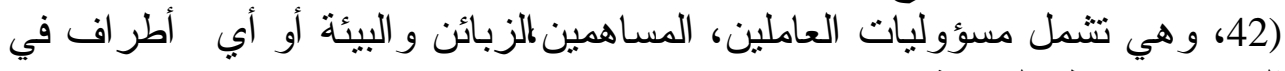
المجتمع تزتبط بالثركة. إن غرض ترن المعايير الأخلاقية هو تدنية حالات تكرار السلوك غير الأخلاقي

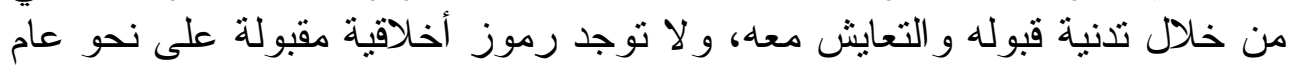

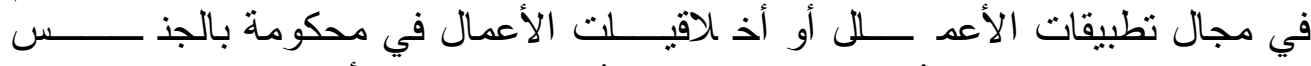

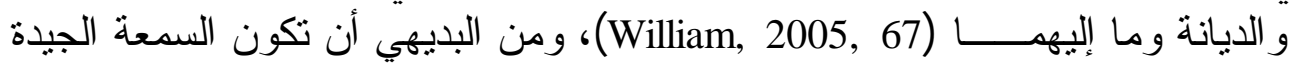

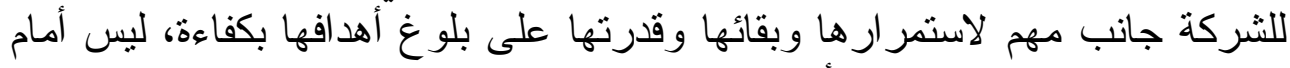

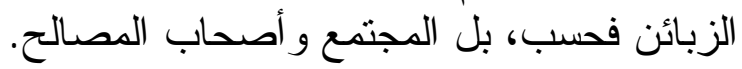

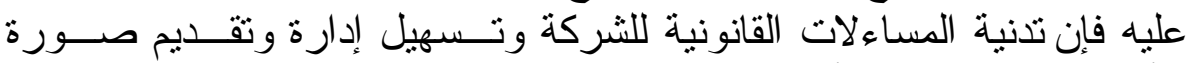

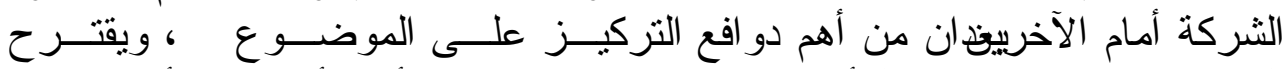
(Greenwood, 2000, 73) الأعمال وهي: الجدول ال.

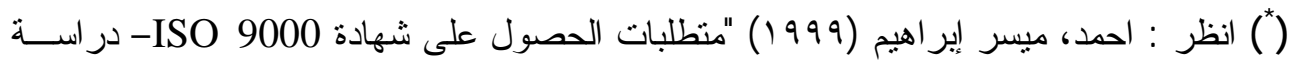

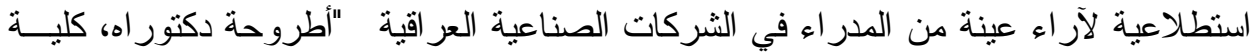

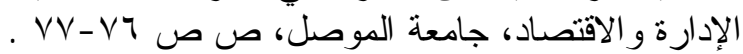




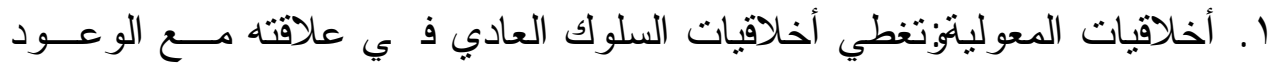

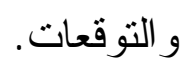

r. أخلاقيات المو ارد البشرية: وتتضمن أخلاقيات القيم الإنسانية.

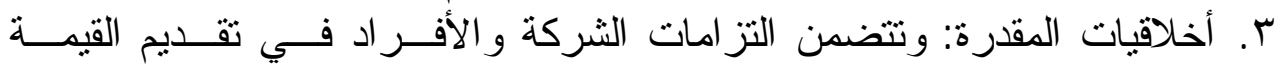

ع. أخلاقيات المستقبل: وتتضمن القلق و الاهتمام تجاه البيئة و الثروة القادمة.

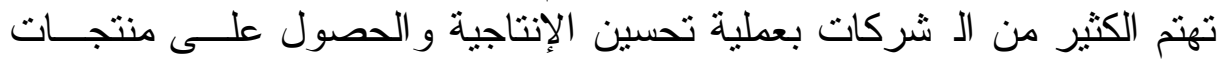

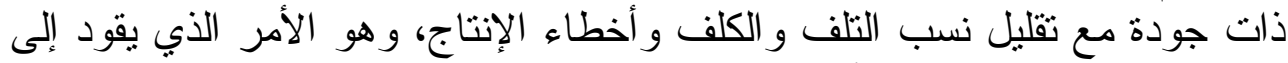

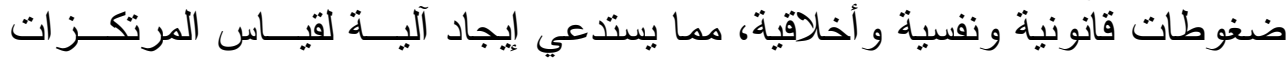

الأخلاقية من خلال عدد من المتغير ات لعل من أَهمها الآتي: (Dilworth,1996, 58)

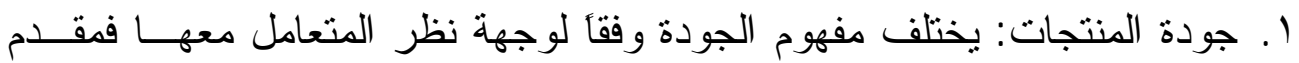

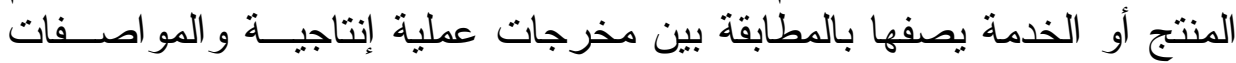

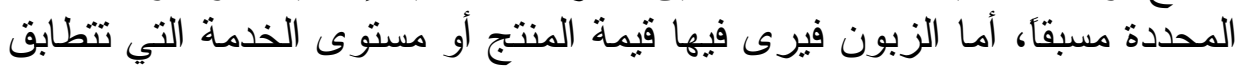

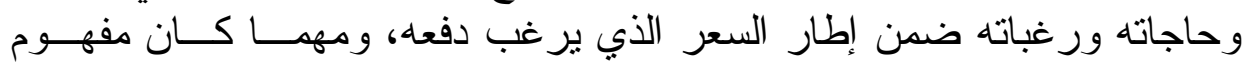

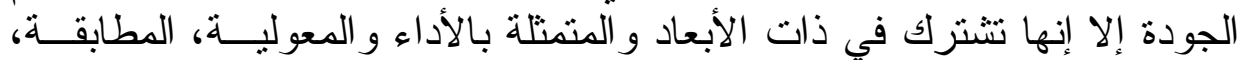

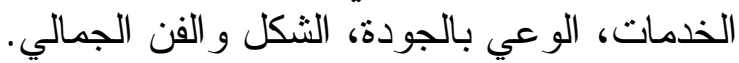

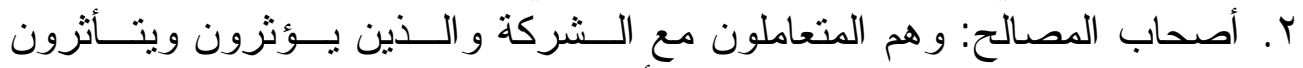

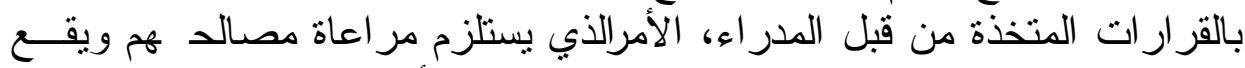

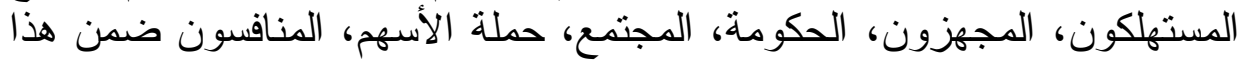
التبويب.

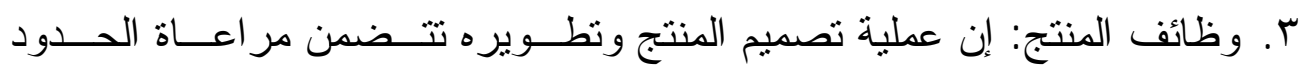

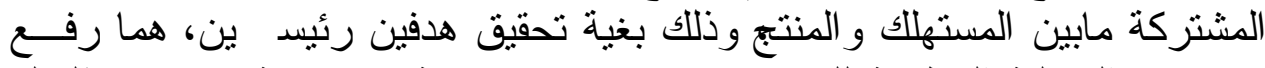

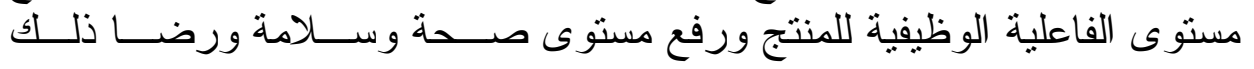




\begin{tabular}{|c|c|c|}
\hline ، قياس المرتكزات الأخلاقية & & \\
\hline الفقرات & 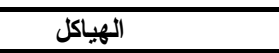 & $ت$ \\
\hline الإعلان، أصحاب المصالح، الثقة، تطابق المخطط مع المنفة. & أخلاقيات المعولية & $T$ \\
\hline المساو اة، التزقبة و التزفيع، الاعتبار ات الاجتماعية، الخذمات. & أخلاقيات المو ارد البشرية & $\bar{T}$ \\
\hline المنافسة، تقارير الأداء، قابليات الأفر اد. & أخلاقيات المقدرة & $\Gamma$ \\
\hline البيئة، التطوير، الأمان، الخطط الطويلة المدى، المعرفة و الإدر الك، الربحية. & أخلاقيات المستقبل & $\varepsilon$ \\
\hline
\end{tabular}

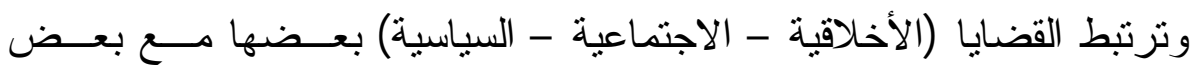

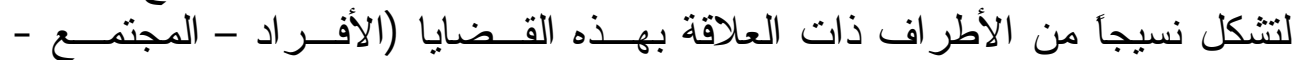
الحكومة) على التو الي، ويمكن أن يعبر عن هذه القضائ القافة بخمسة أبعاد اعتبارية هي:

(Kenneth \& Jane, 2006, 37)

Information Right \& Obligations ـ حقوق المعلومات و الالتز امات الخاصة بها

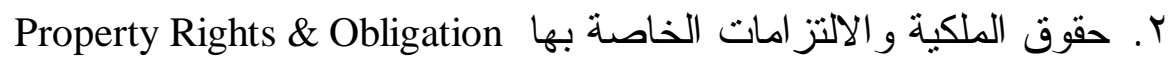
r. المساءلة و الملكية Accountability \& Control

ع. جودة النظام System Quality

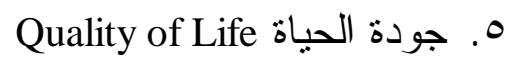

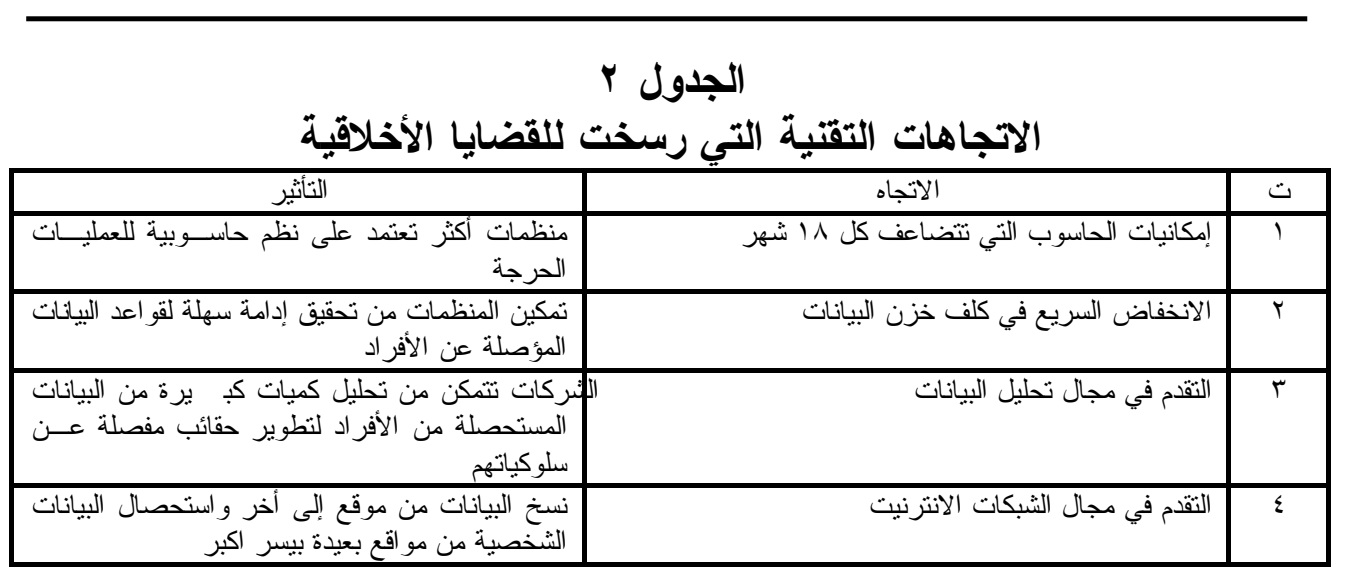

Source: Kenneth ,C. L. \& Jane , P. L. (2006) "Management Information Systems", Pearson -Prentice Hall.

\footnotetext{
ويضيف هؤ لاء أن هناك خمس خطو ات متاحة أمام المنظمــات فــي تحليـلـ القضايا الأخلاقية، وهي: الاهي:

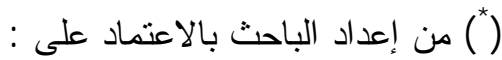

- Greenwood ,Michelle R., (2000), "The Study of Business Ethics : A case For Dr Seuss "

, A European Review, Vol.9 ,No.3 . 
1. التحديد و الوصف الو اضح للحقائق (من فعـل مــاذا؟ لمــن؟ و أيسـن؟ ومتــى؟

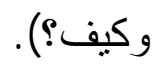

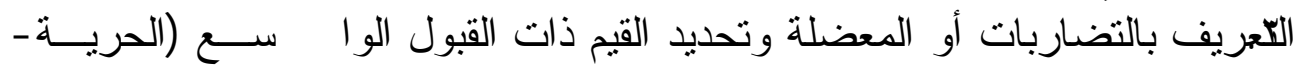

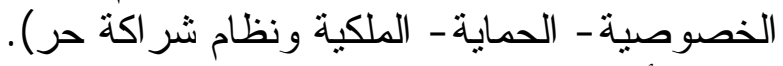

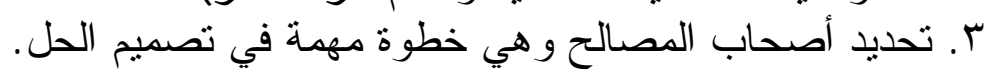

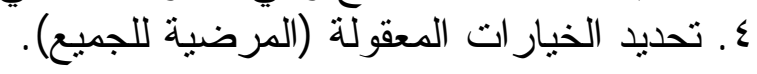

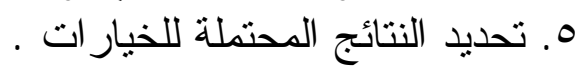

\section{ثنانياً - مفهوم إدارة الجودة و أخلاقياتها}

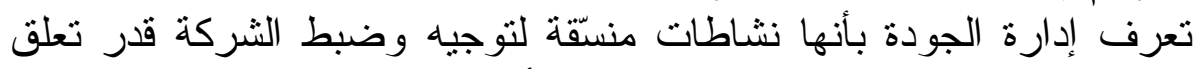

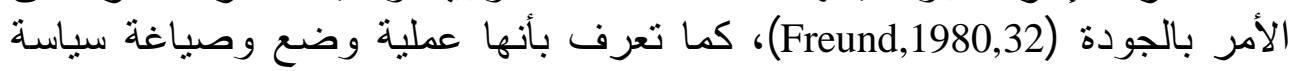

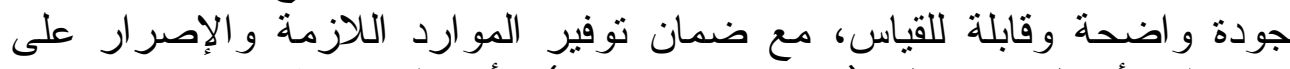

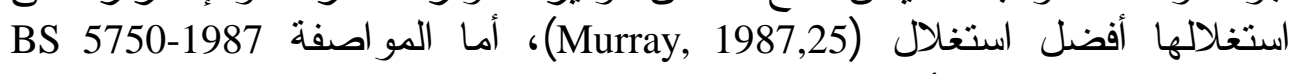

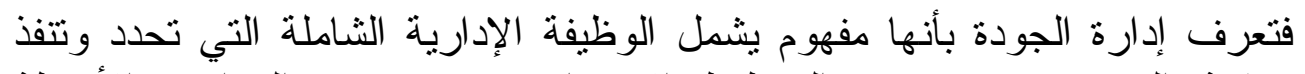

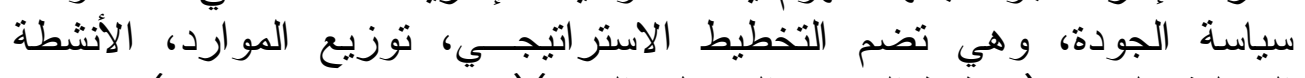

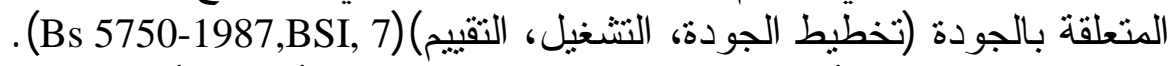

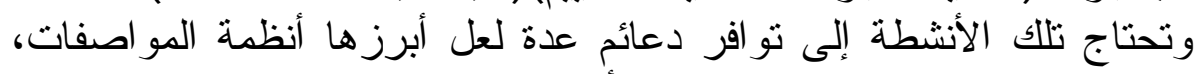

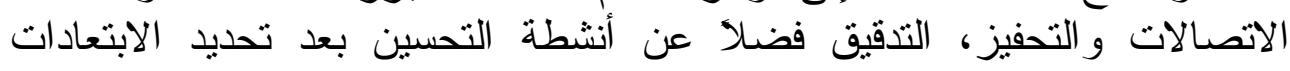
ونتخيص مسبباتها.

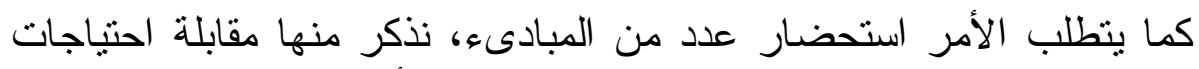

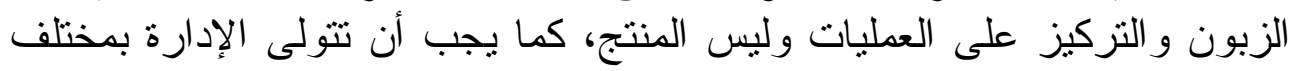

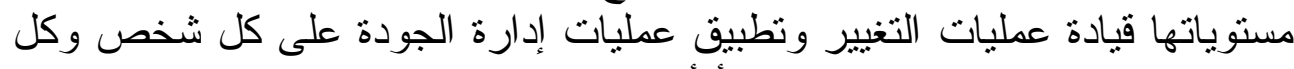

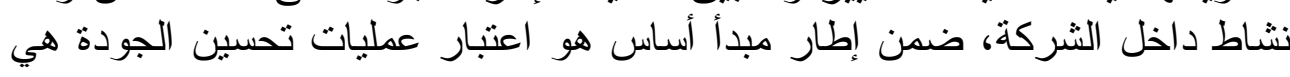

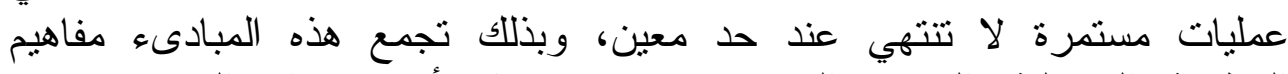

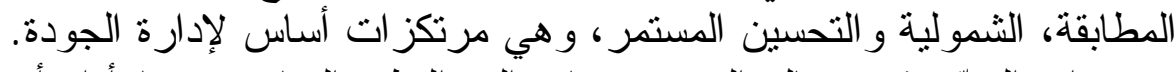

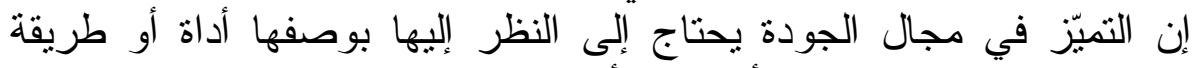

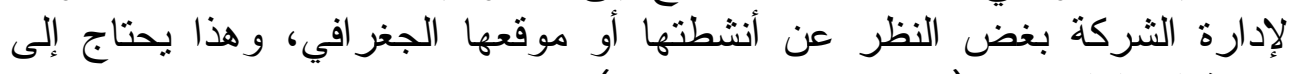
خمسة إجر اءات هي: (Feigenbum,1982, 72)

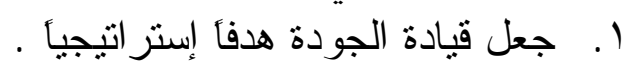

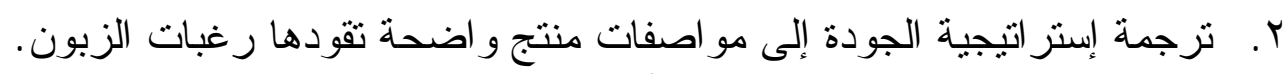

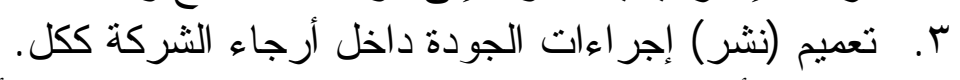

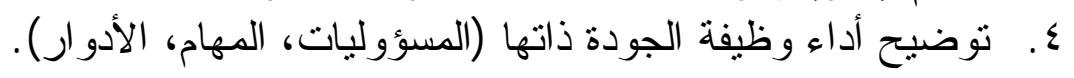

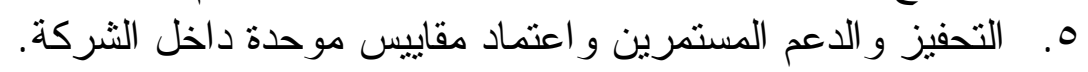

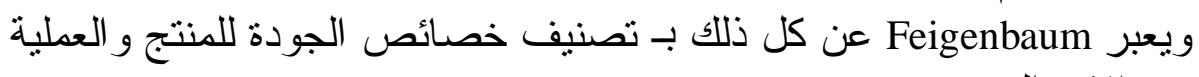
Customer Use -Oriented Classification Of Product \& نحو استعمالات الزبون 
Process Quality Characteristics

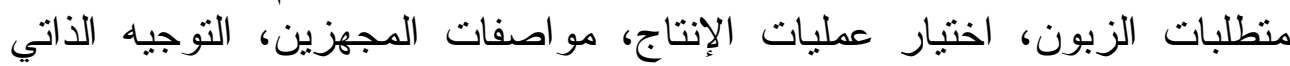

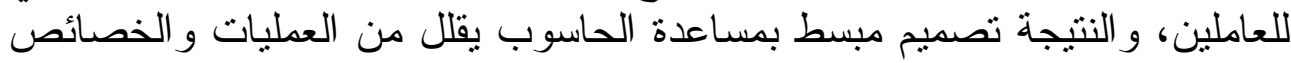
غير الضرورية، وهو ما بعرف بمفهوم نشر وظيفة الجودة .Deployment (QFD) إن حالة التتافس الثائعة في أسواق اليوم دفعت العديد من الثركات إلى الى الثى

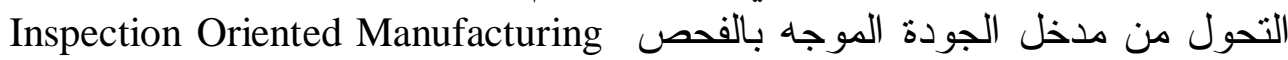
Focused

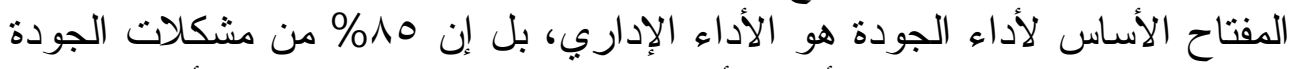

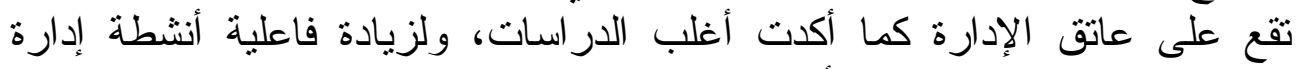

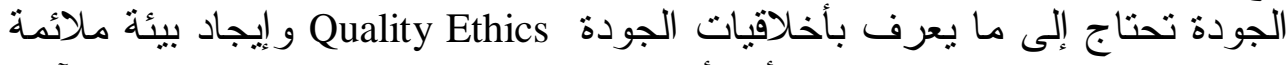

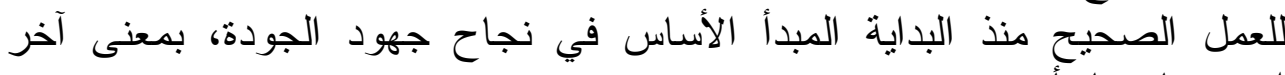

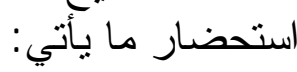

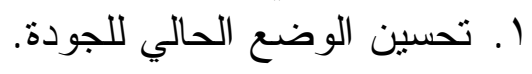

r. إعلام الزبون عن ذلك التحسين و عن التضاربات المحتملة للمصالح عند تتفيذ العقد معه.

r. التحول من المطابقة للمتطلبات إلى المطابقة مع التوقعات بعد أن تحدد بدقة وشفافية.

Simultaneous ع. التحول من التصميم الهندسي إلى الهندسة المتو افقة (المحاكية) .Engineering

○. تحمل المسؤولية عن الجودة، المعولية، و السلامة وهي مسؤولية لا بمكن تفويضها. 7. التخلي عن التطرف أمام الزبائن، العاملين، والنظر اء وفقاً لاعتبار ات الجنس و الديانة و المعتقد

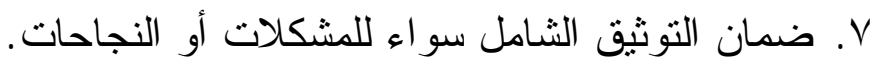

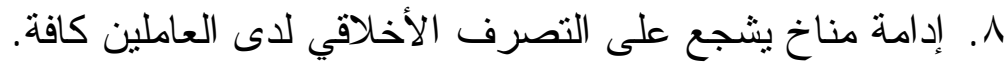

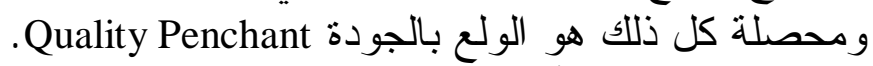

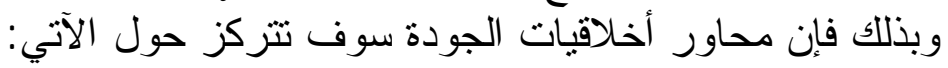

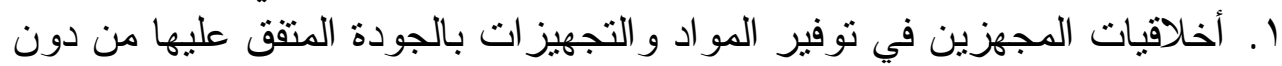
تحايل أو تجاوز المتطلبات الداخلية (الأداء) على حساب المظهر التهر و الثكل.

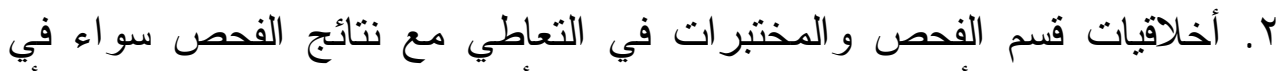

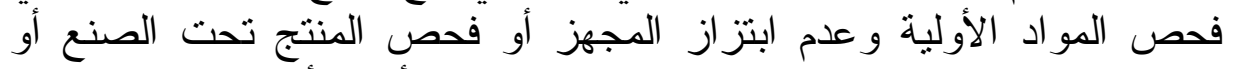

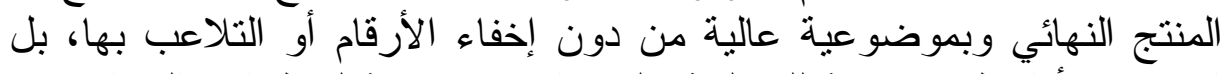

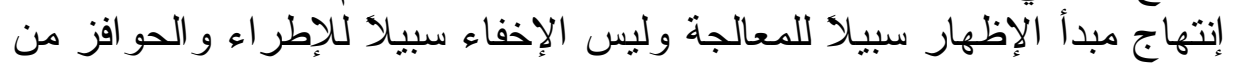




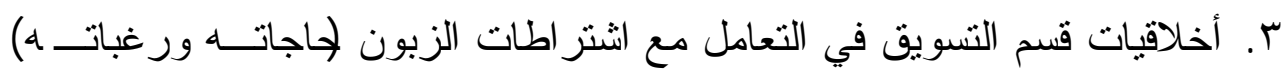

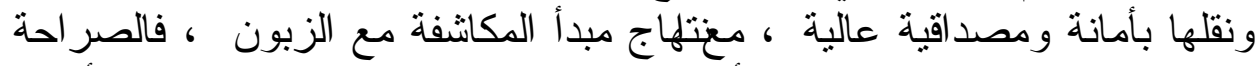

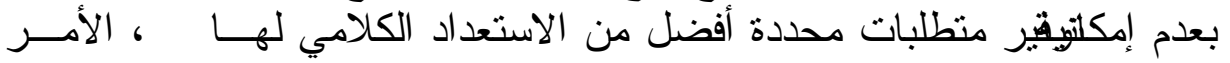

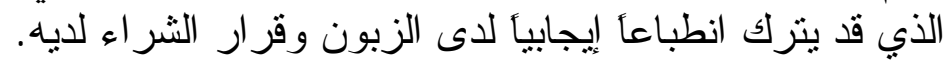

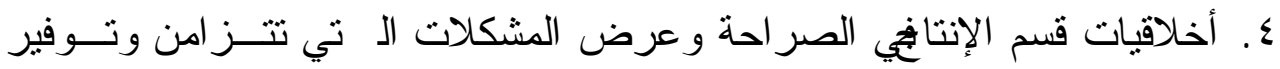
شروط المواصفة ومظاهر الفثل المحتملة.

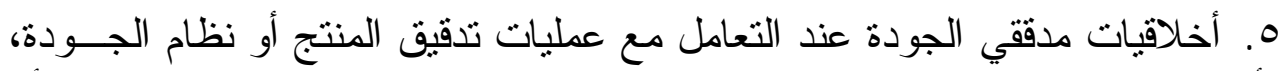

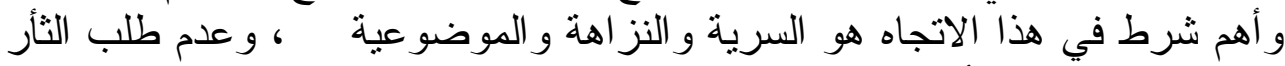

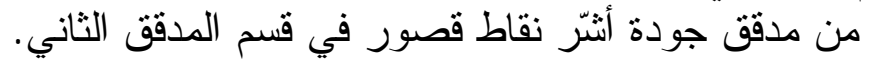
T. أخلاقيات الإدارة العليا و إدارة الجودة في في التعامل مع:

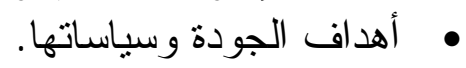
• • اجات الزبون من منطلق النقة المطلقة و الصر احة و المكاشنفة.

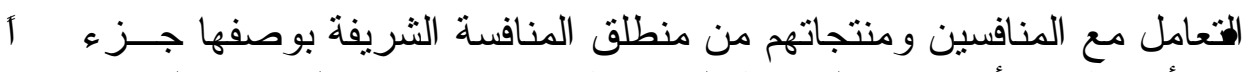

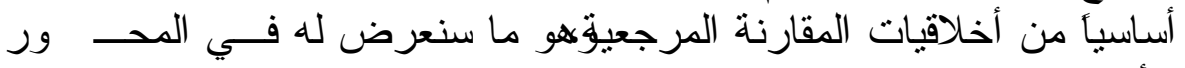
الأتي.

ثالثًا - أخلاقيات المقارنة المرجعية

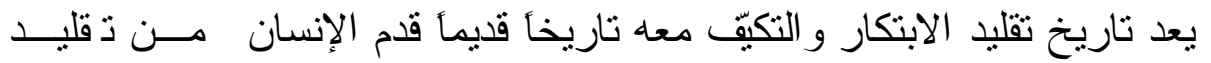

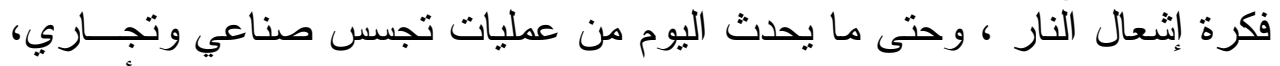

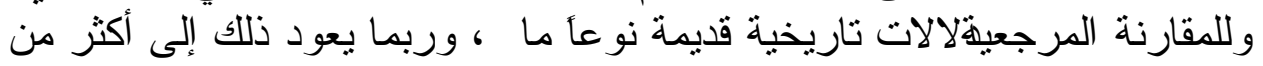

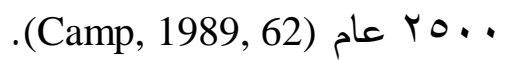
وفي مطلع القرن التاسع عشر سافر الصناعي الأمريكي Francis-Lowell إلى التى

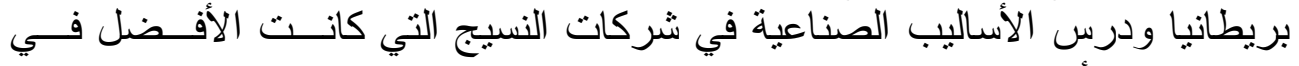

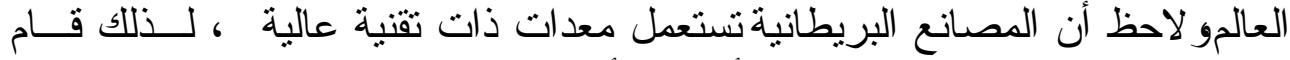

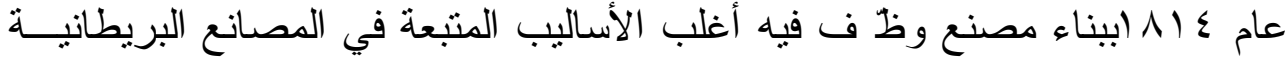

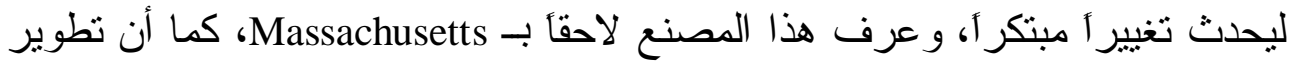

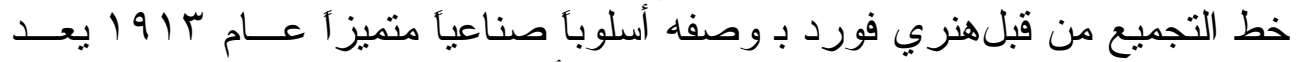

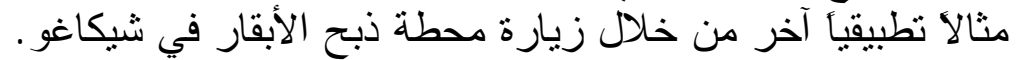

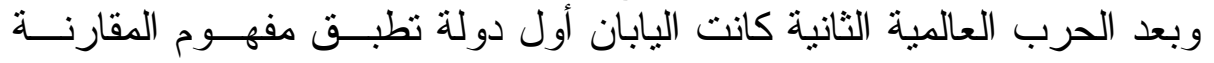

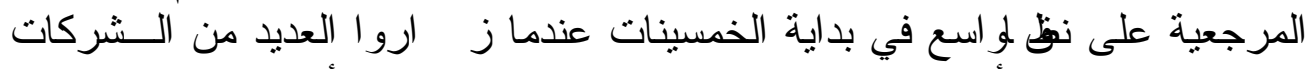

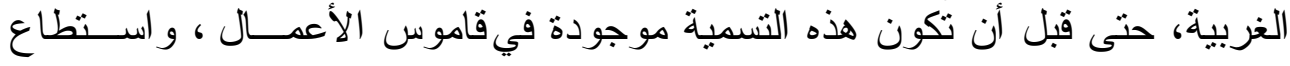

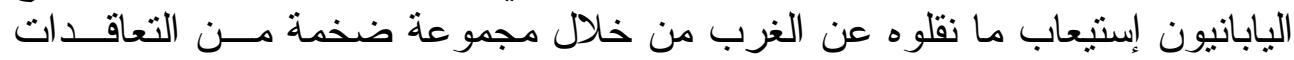

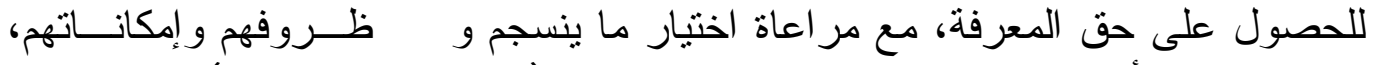

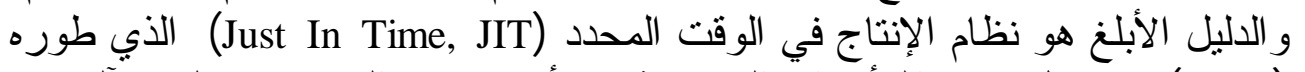

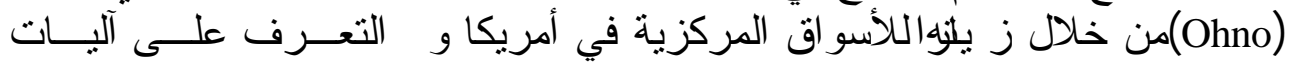




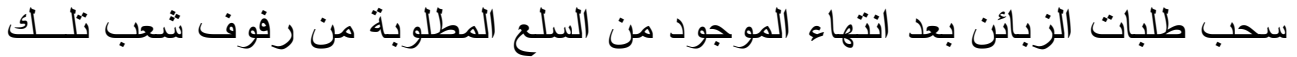

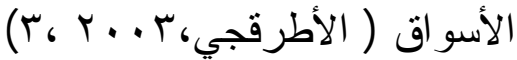

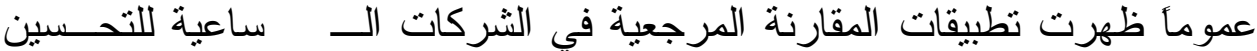

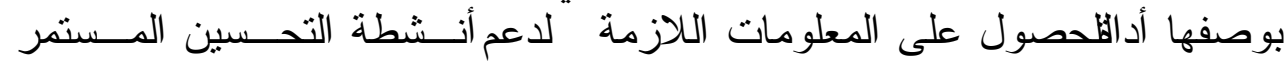

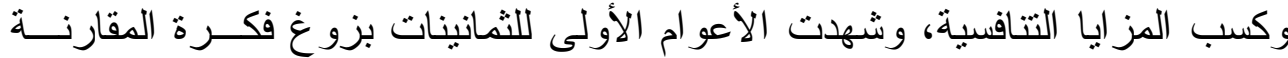

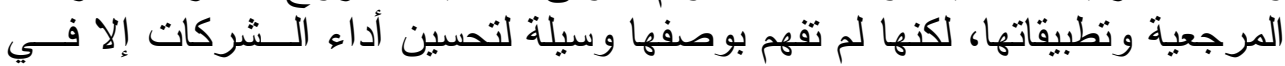

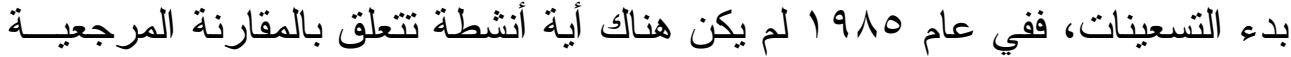

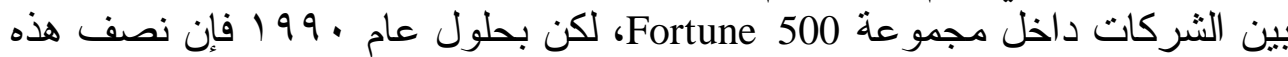

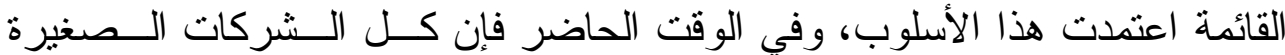

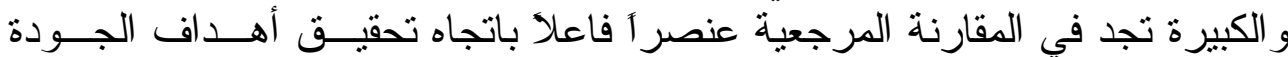

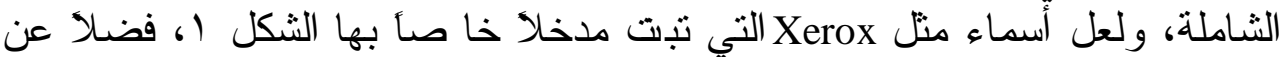

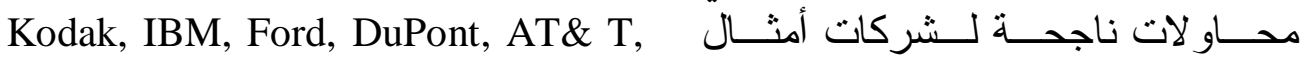
Motorola,

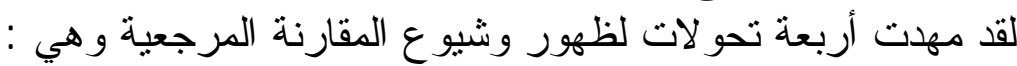

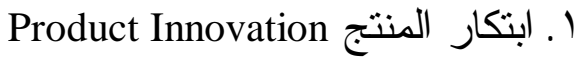
Product Development r. تطوير المنتج

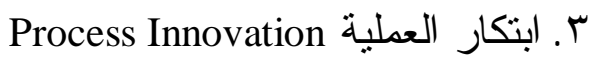
ع ـ حيازة التكنولوجيا Technology Acquisition

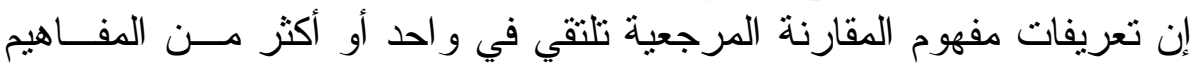

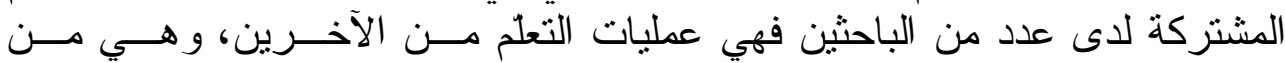

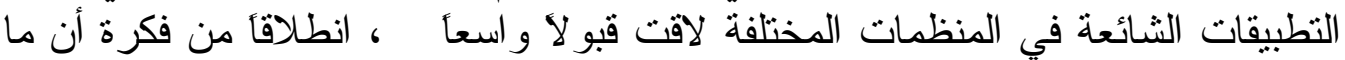

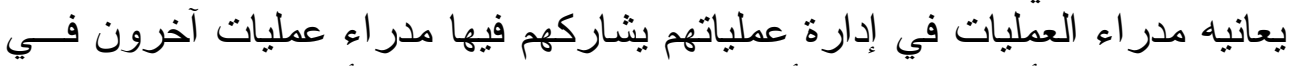

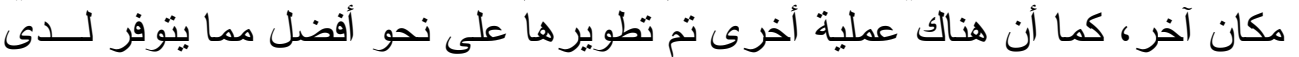

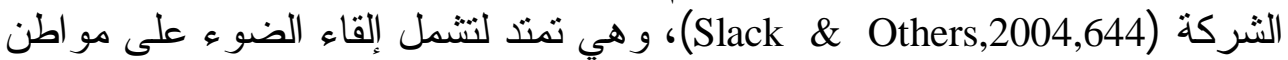

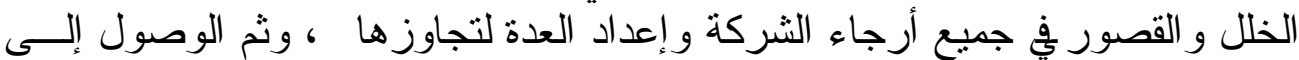

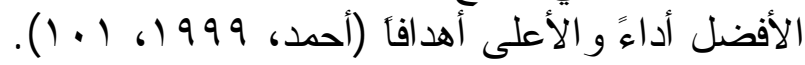

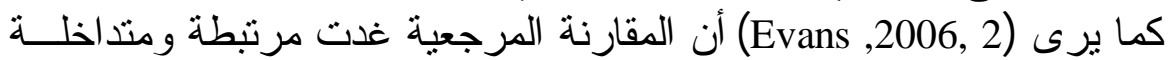

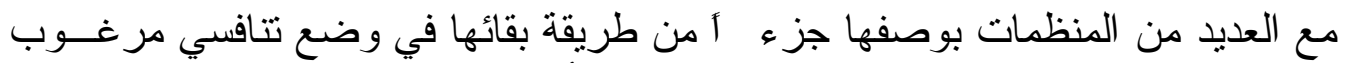

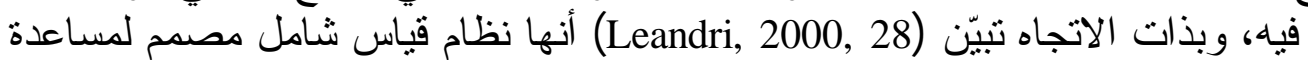

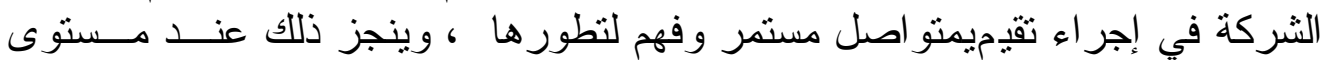

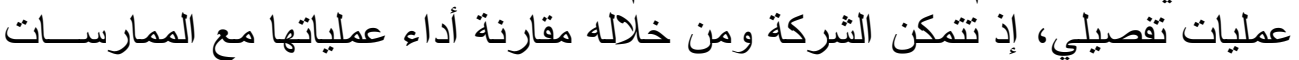

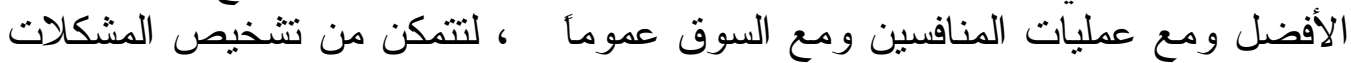

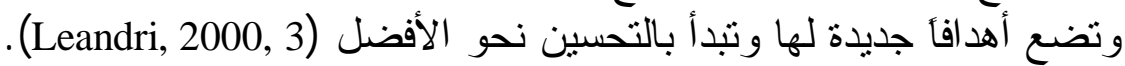



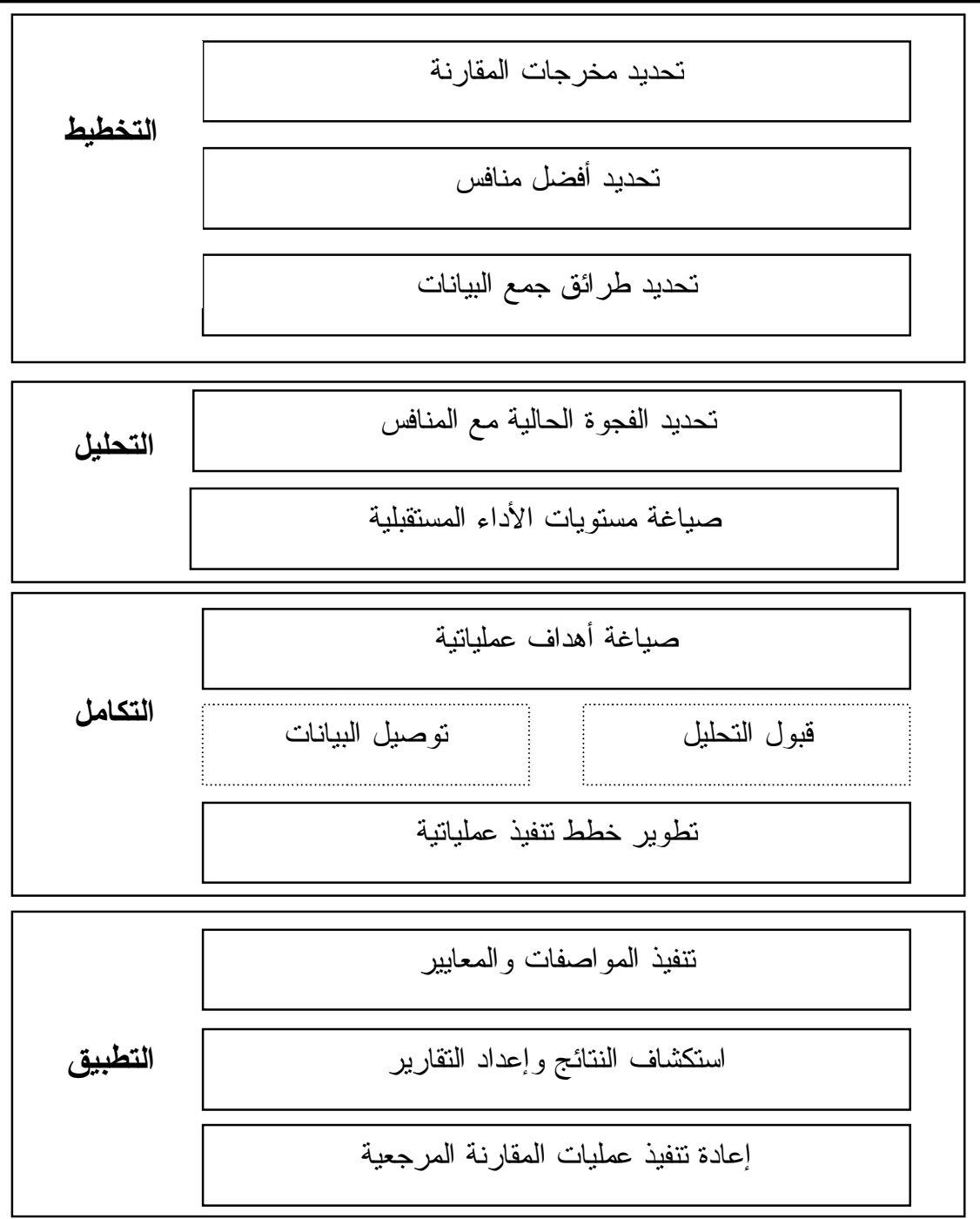

النضج

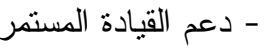

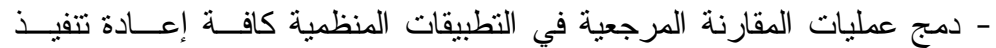
عمليات المقارنة المرجعية

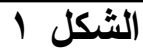

عمليات المقارنة المرجعية لاى ل

- Slack, Nigel, chambers ,S. \& Johnston, R.(2004)“'Operation Management “ Prentice Hall, Essex , UK, P.645 . 


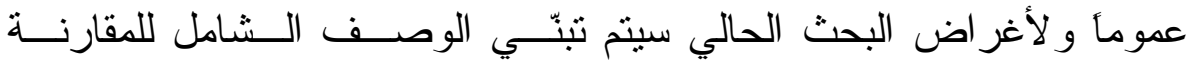

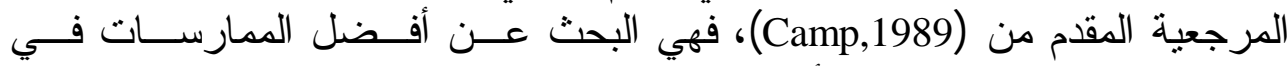

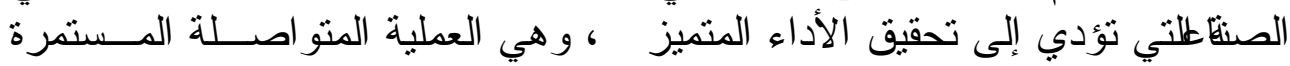

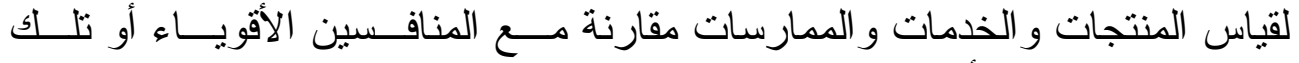

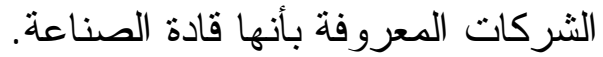

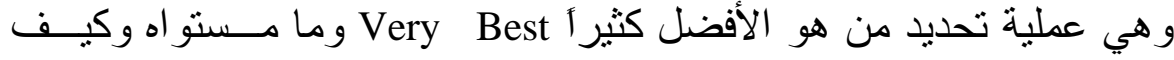

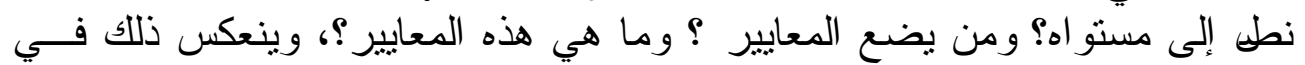

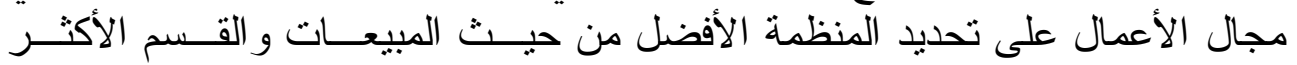
استجابة للزبون و عمليات التصنيع الأكثر رشاقة Leanest و آليات تكيــيم المعــايير . (John, 2006, 2)

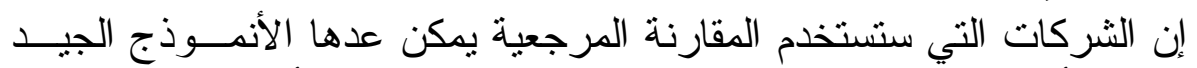

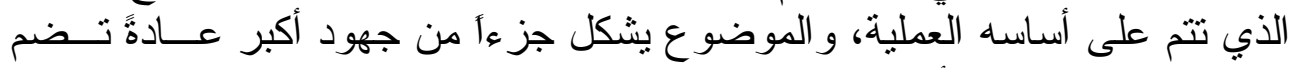
إعادة هندسة العمليات أو عمليات تحسين الجودة العيات

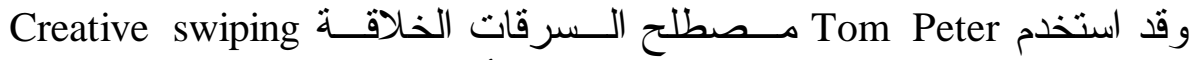

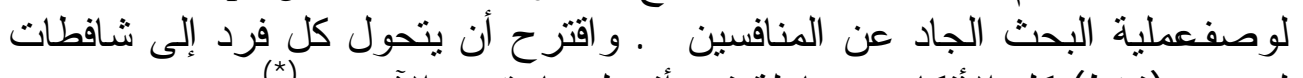

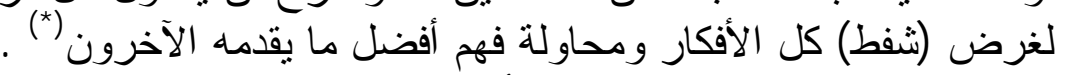

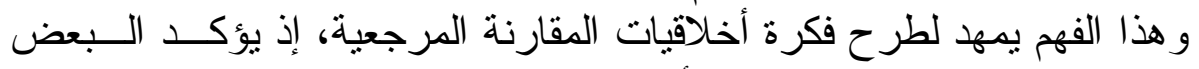

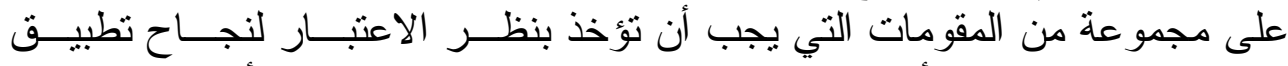

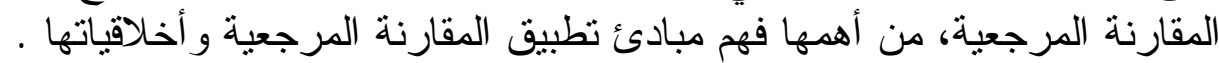

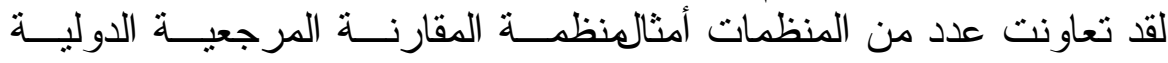
International Benchmarking Clearing House

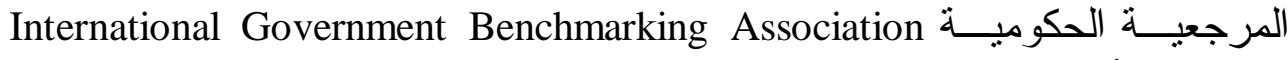
و المركز الأمريكي للإنتاجية و الجودة American Productivity \& Quality Center

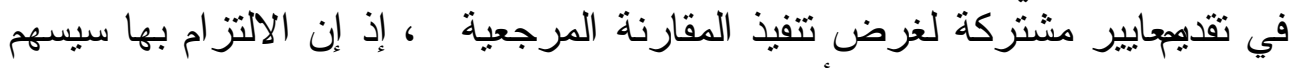

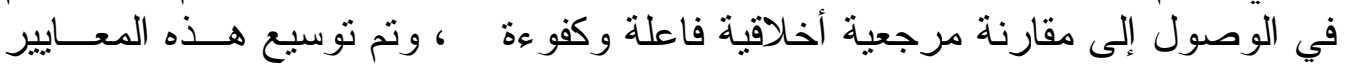

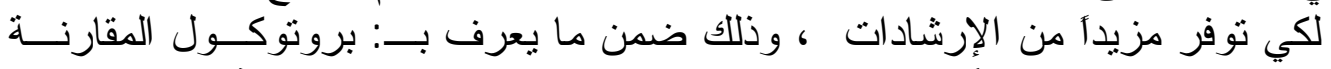

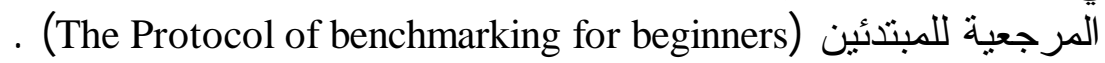

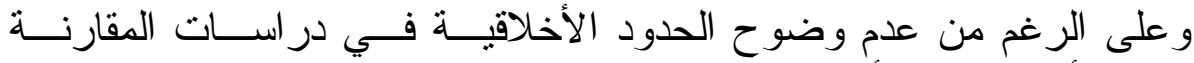

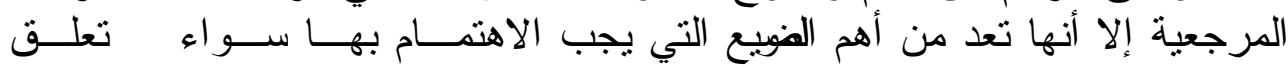

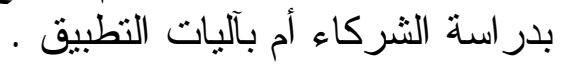

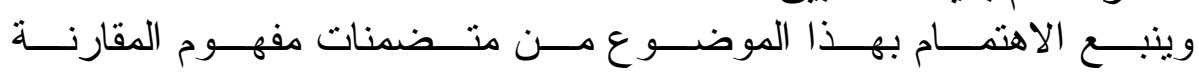

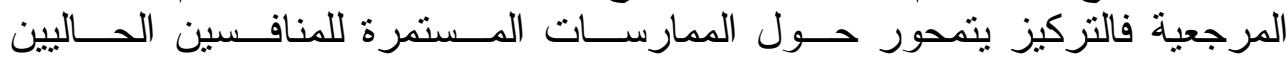

$$
\text { : انظر في ذلت }
$$

Russell, Robert, S. \& Taylor 111, Bernard, W. (1995) "Production and Operations Management focusing on Quality and Competitiveness“ prentice-Hall, Inc, Englewood Cliffs, p. 215. 


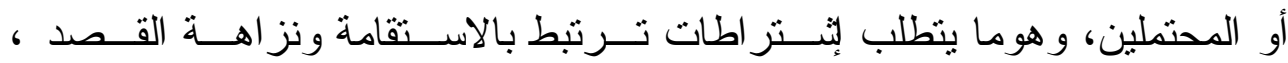

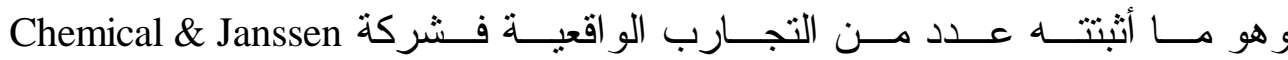

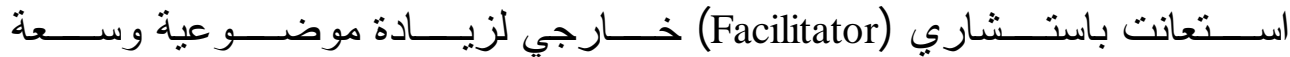

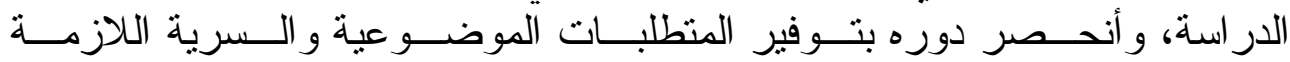

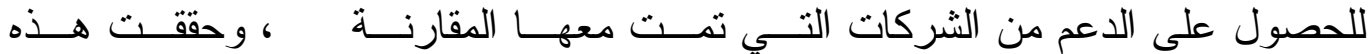

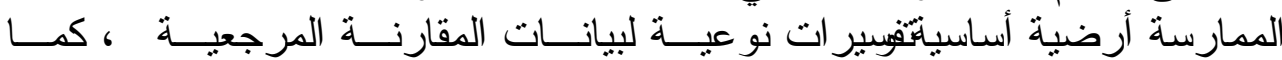

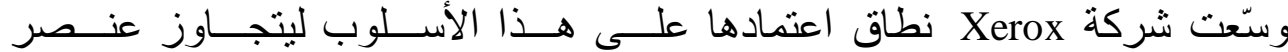

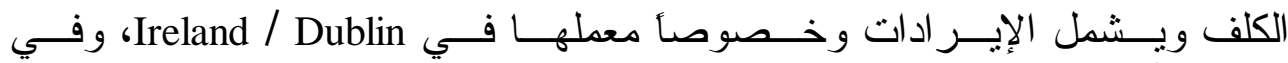

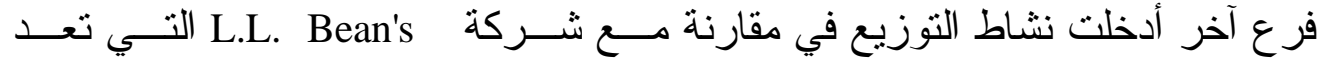

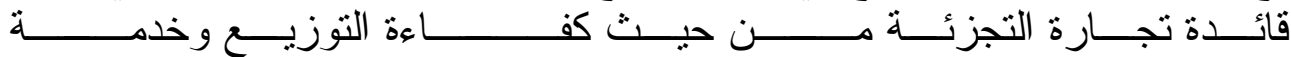

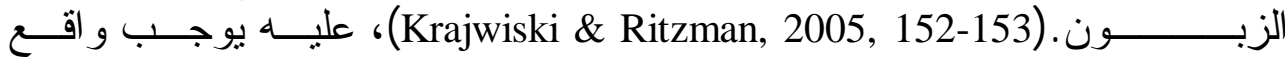

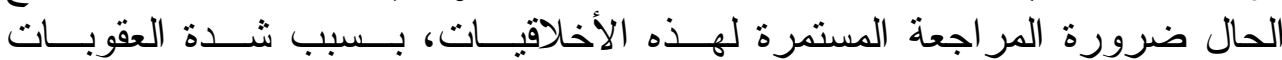

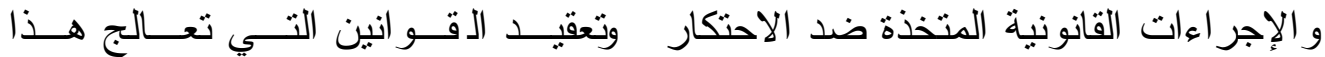

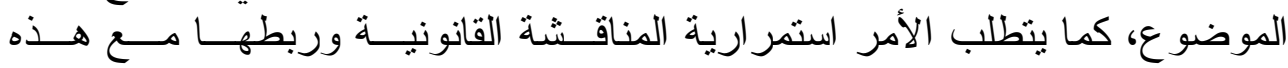

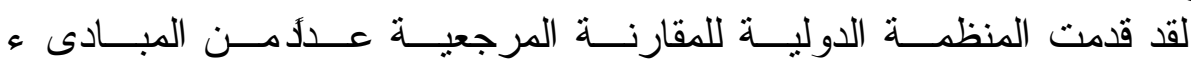

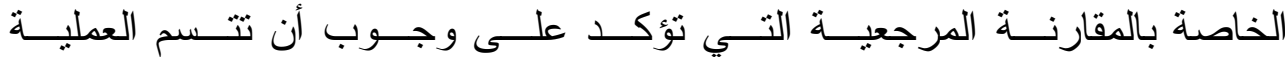

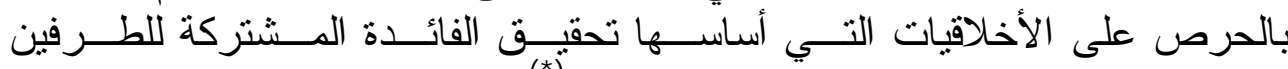

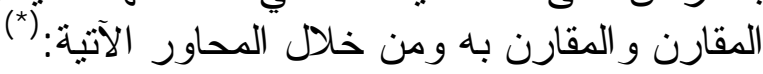

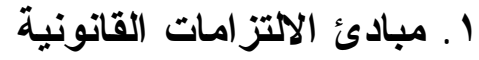

أ. إذا كان هناك أبي شك محتمل حول قانونية أبي إجــر اء أو نــشاط معـين، فــلا تدخل في ذلك النشاط.

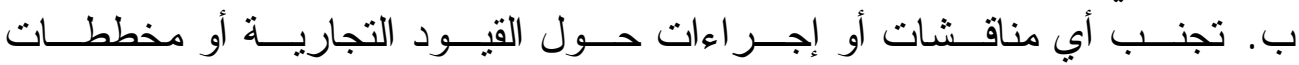

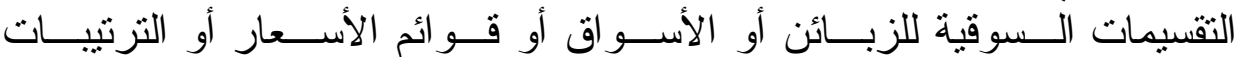

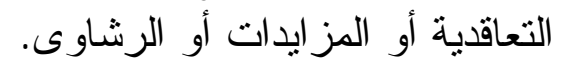

ت. للإججام عن الأسرار التجارية بو ساطة أية وســيلة يمكـن أن تفـسر بــشكل

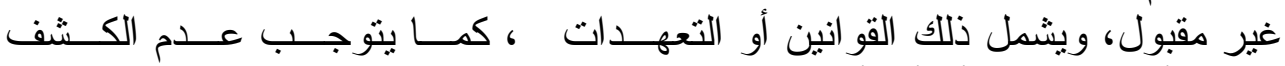

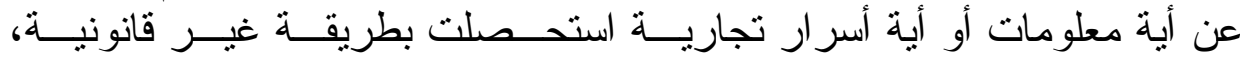

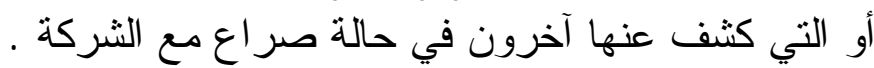

1- Finance-Benchmarking, FAQ, (2001), Benchmarking, Ethics, http:11 www. Finance, gov.au/benchmark/benchmarking ethics. htm/, PP. 1-3.

2- www. Igba.org. ethical. essues .fedral ,state , jan.2007. 


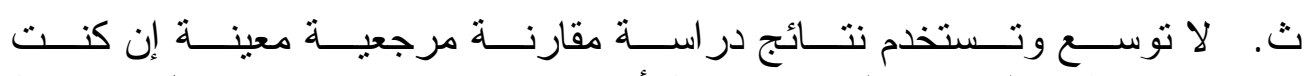

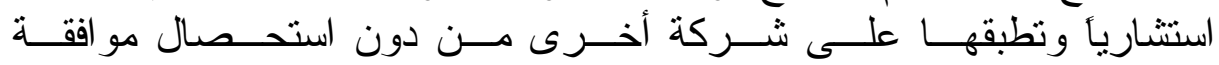
الثركة التي أجريت معها المقارنة المرجيات المعية الأولى .

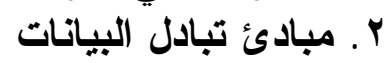

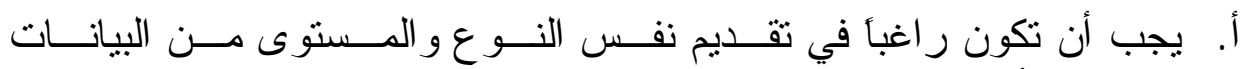
التي تريد أن تطلابها من شريك اغن المقارنة المرجعية.

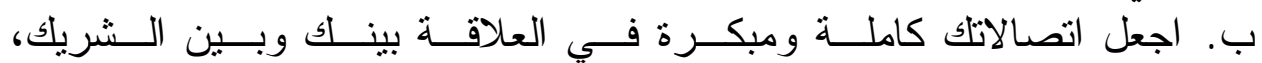

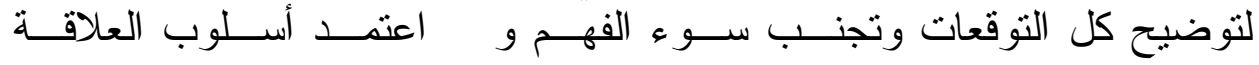

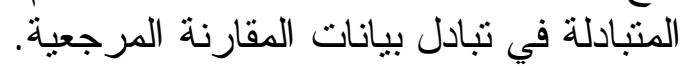

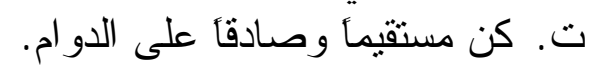
ب. مبادئ السرية من منية

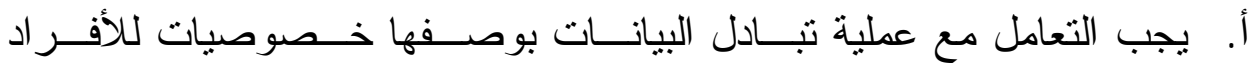

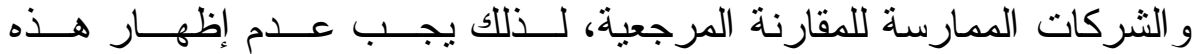

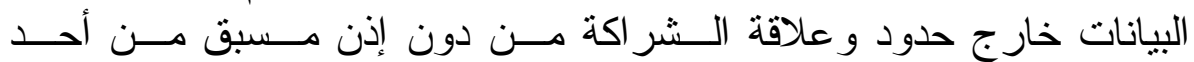
الطر فين. - مات ب. يجب أن تبقى مشاركة أي شركة في در اســة المقارنـــة المرجعيـة ســرية ويجب تجنب الاتصالات الخارجية من دون إذبن فئن دسبق.

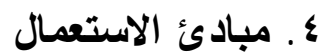

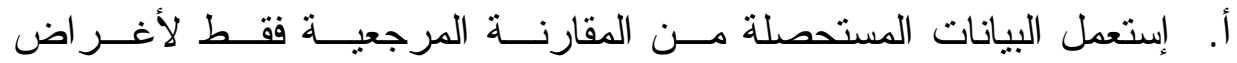

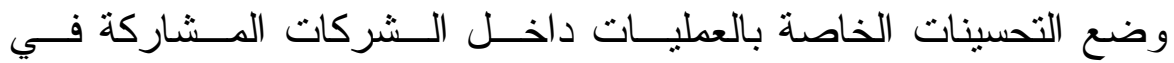
العملية.

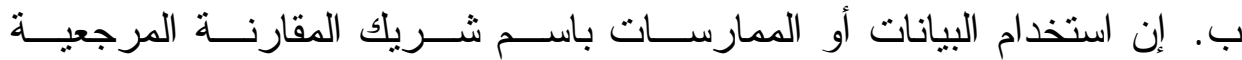
يتطلب مو افقة مسبقة من ذلك الثريك.

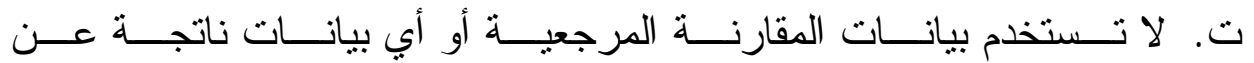

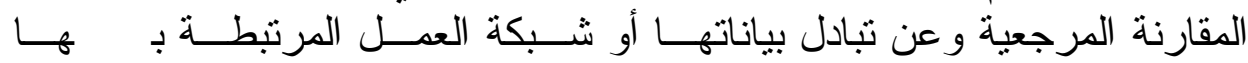

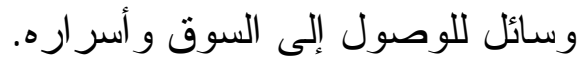

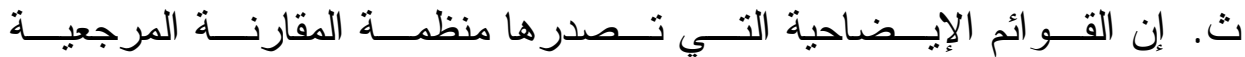

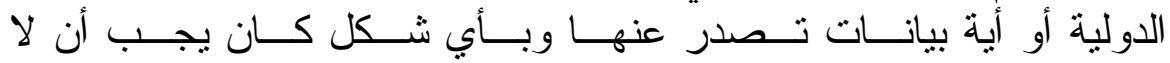

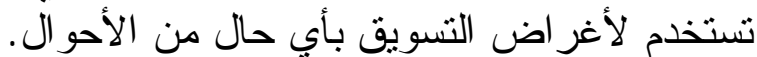

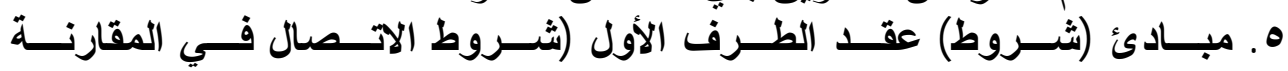
(المرجعية)

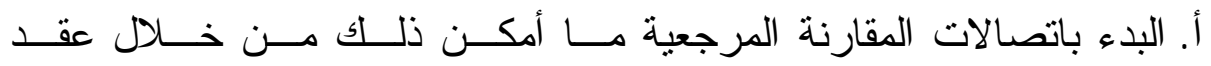
مقارنة مرجعية تتظمه الثركة الثريكة.

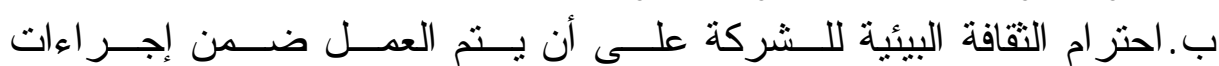
متفق عليها على نحو متبادل. 


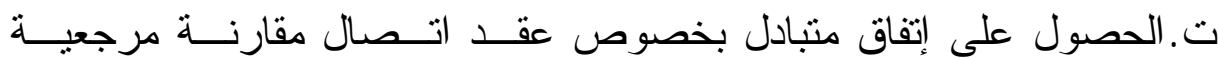

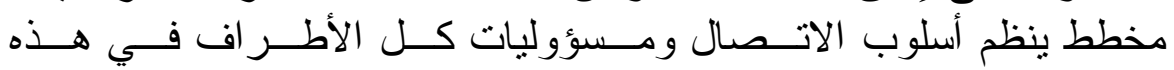

$$
\text { 7. مبادئ اتصال (عقد) الطرف الثالث }
$$

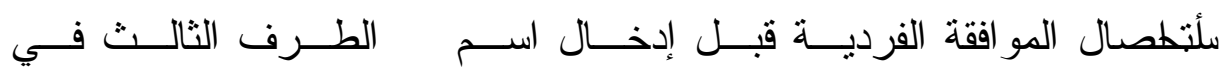

$$
\text { الثر اكة. }
$$

ب.تجنب كثف اسم الطرف الثالث قبل إستحصال إذن مسبق.

V. المبادئ الإعداد (التهيؤ)

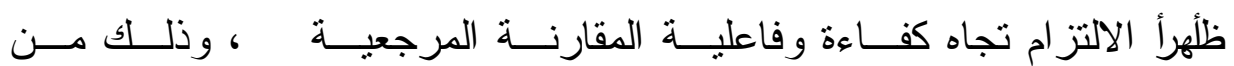

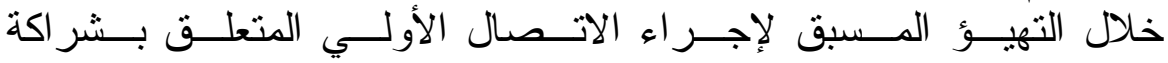

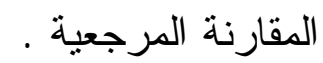

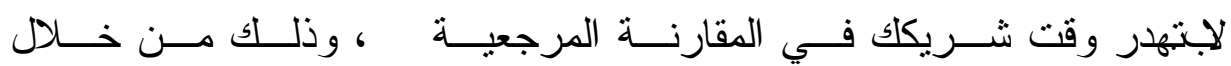

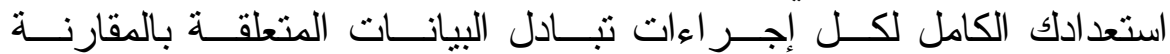
المرجعية .

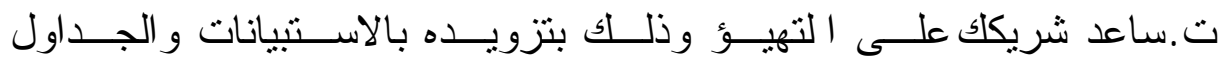

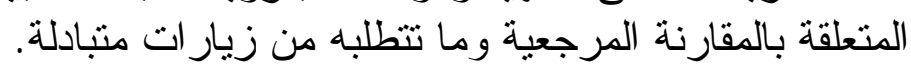

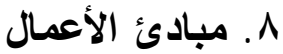
أ. متابعة كل التز ام يجري تجاه الثريك في وقته المحدد.

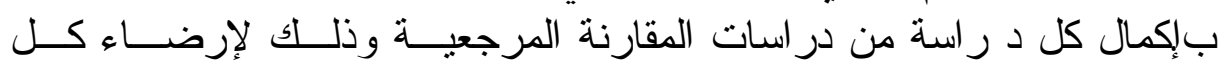

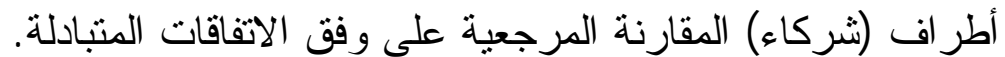
9 ـ. مبادئ التفهم والفعل أنركاء

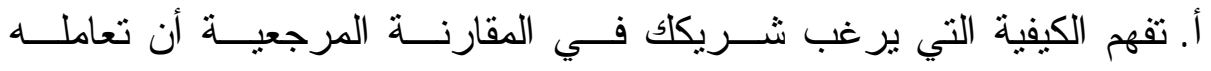

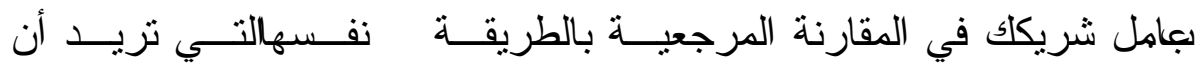
يعاملك بها.

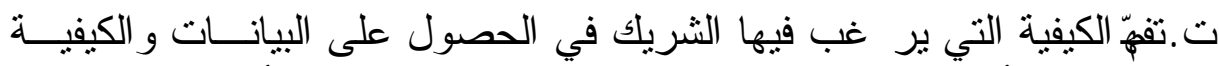

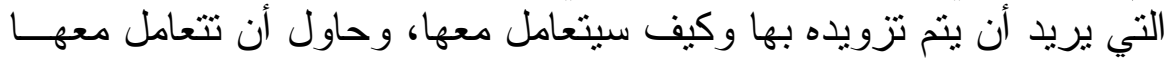

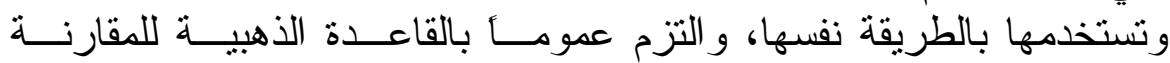

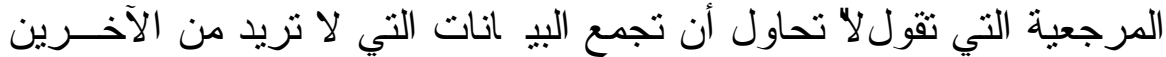

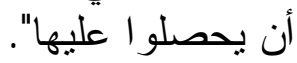


رابعاً - الفرص المتوقعة لإحداث خروقات في قواعد المقارنة المرجعية وسبل الحد

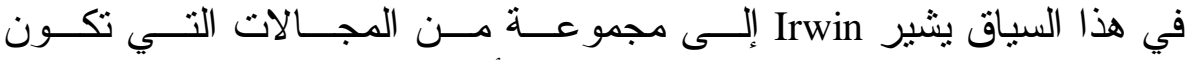

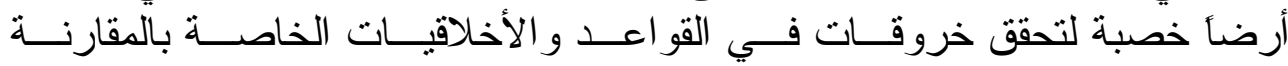
المرجعية ومنها: (Irwin , 1995,1) ا. ال التحدث عن التسعيرة أو عن الكلف الحساسة تنافسياً. r. الط الب من المنافس الإنموذجي بيانات حساسة.

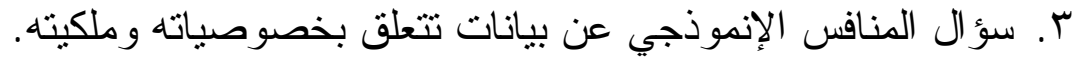

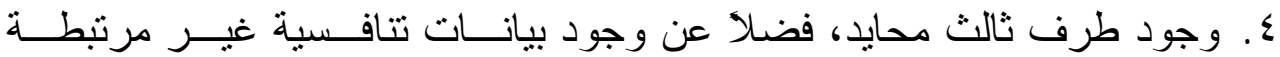
بعنو ان (اسم) معين.

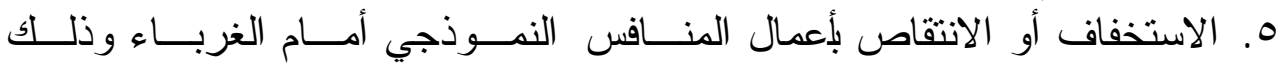

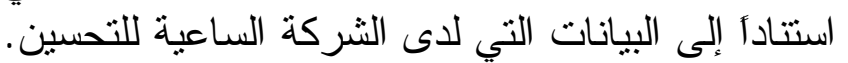

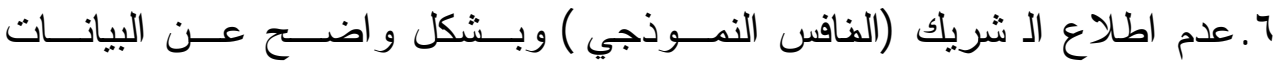

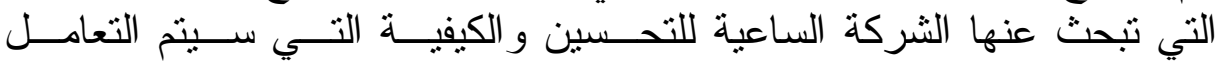
مع هذه البيانات التي ستؤخذ منه. V V ع إبر ام اتفاق رسمي مع المنافس الإنموذجي.

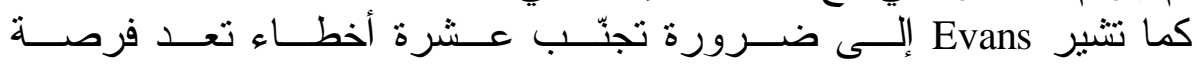

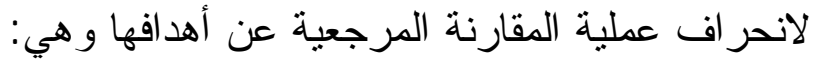

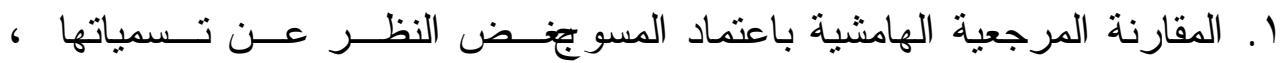

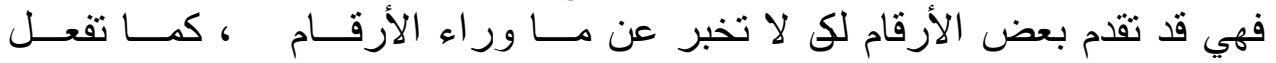
عمليات المقارنة المرجعية النظامية.

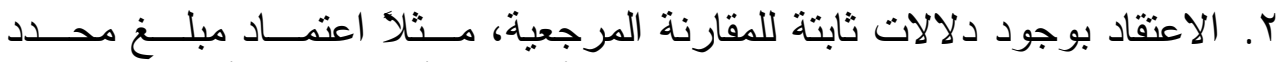

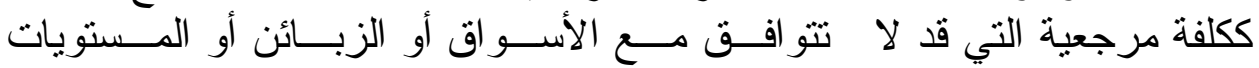

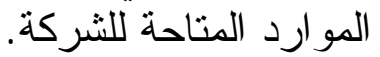

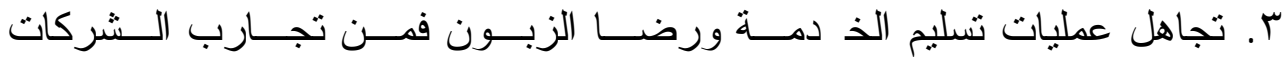

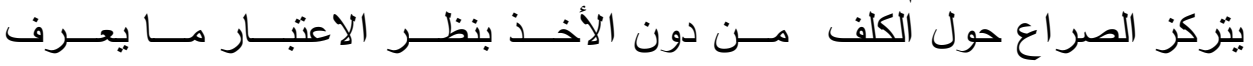

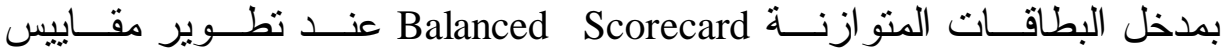

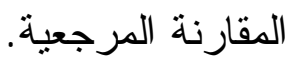

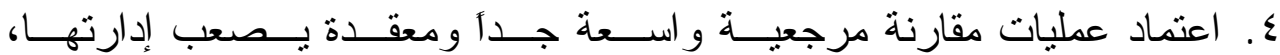

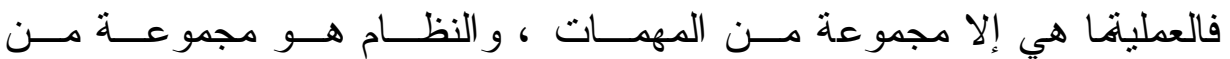

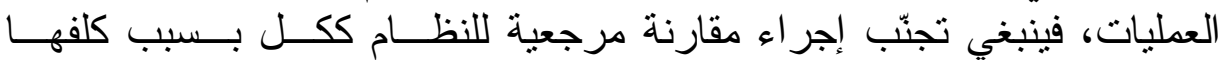

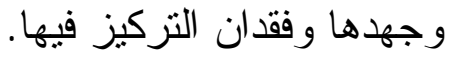

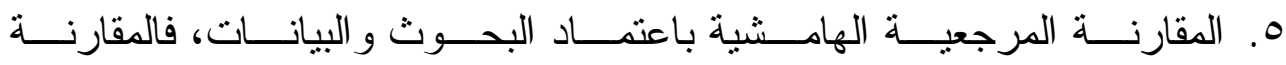

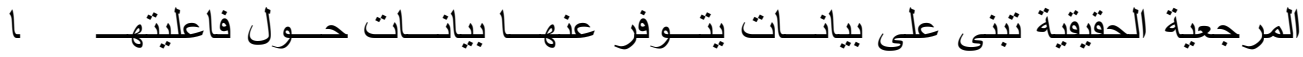
وكلف مو اردها، وليست عمليات نوثيق مستمدة من عمليات مشابهة. 


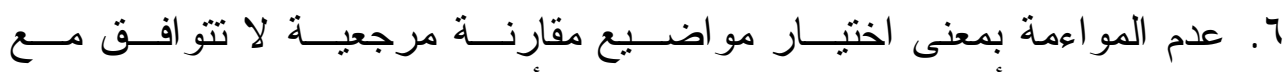

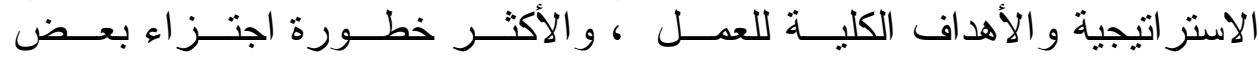

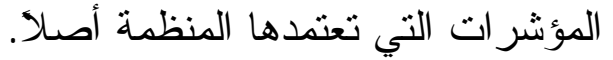

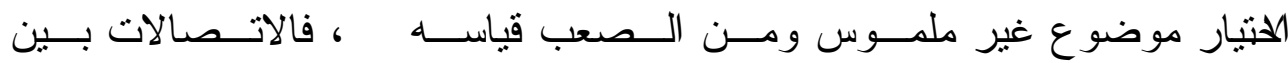

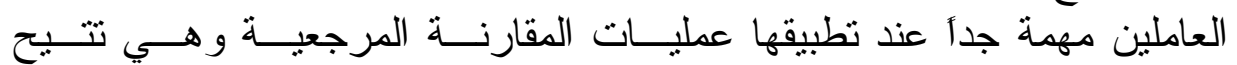

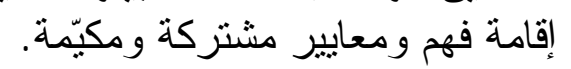

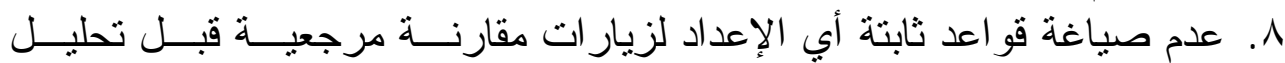

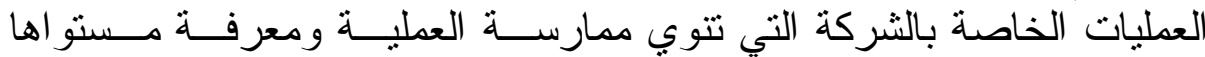

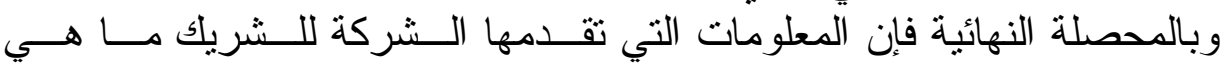

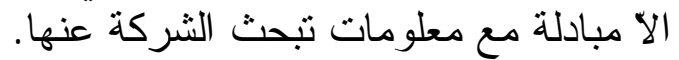

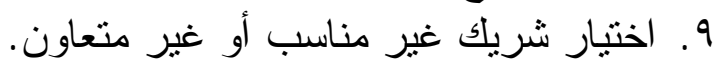

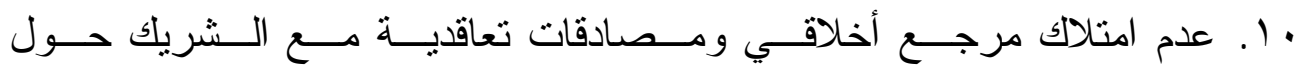

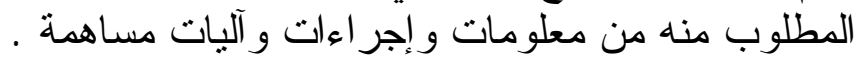

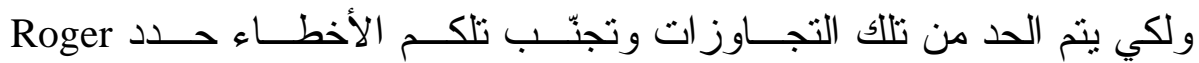

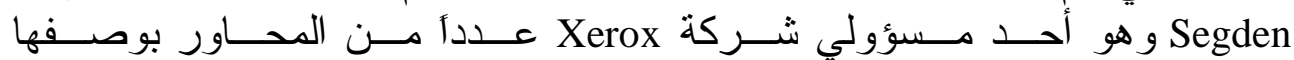

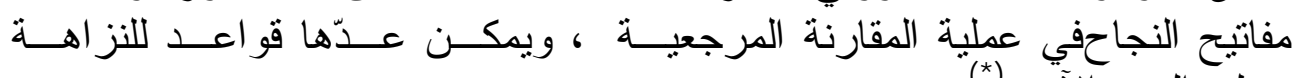

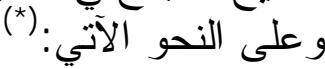

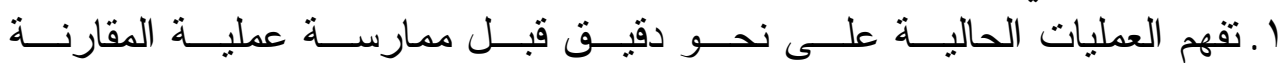

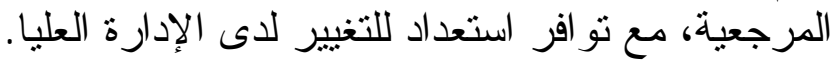

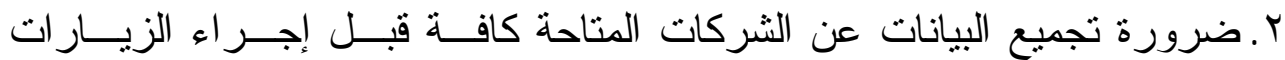

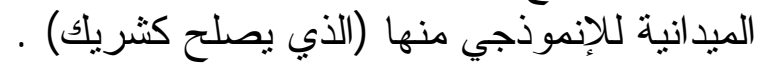

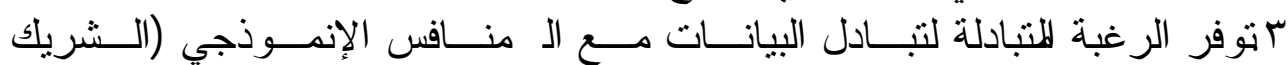

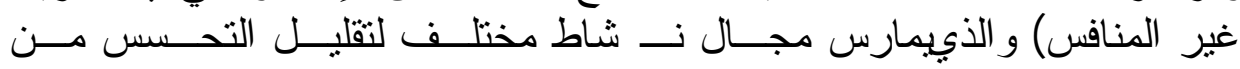
إعطاء البيانات. ع ـ احتر ام سرية البيانات المستحصلة.

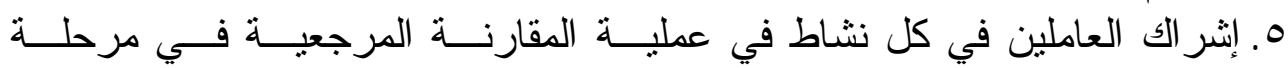

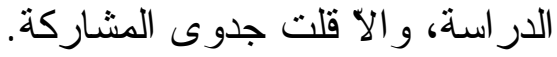
7 7. أن يشمل التركيز على النتائج، و الأساليب و العمليات على العى حد سو اء.

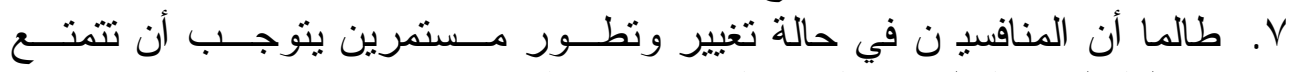
عملية المقارنة المرجعية بصفة الاستمر ارية.

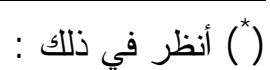

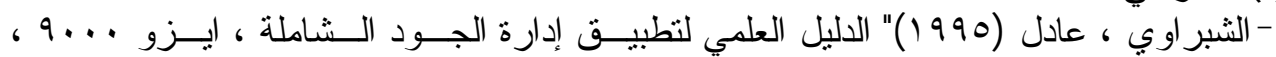

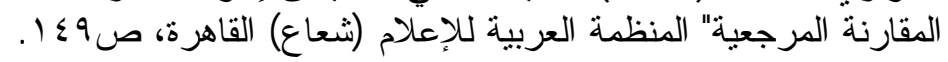




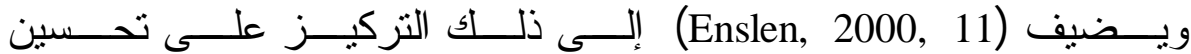

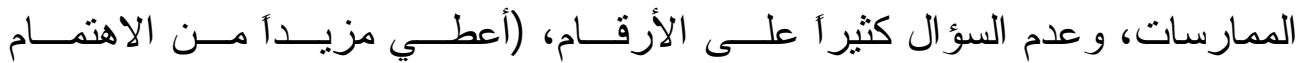

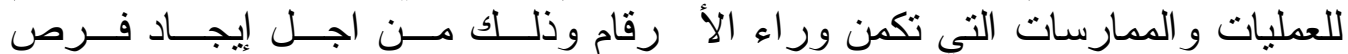

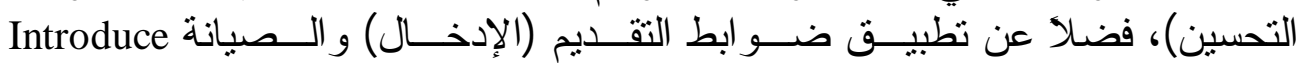
and Maintain Discipline

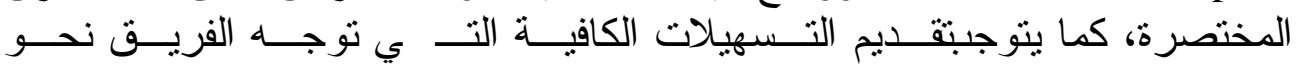

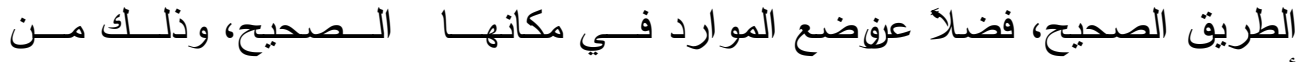

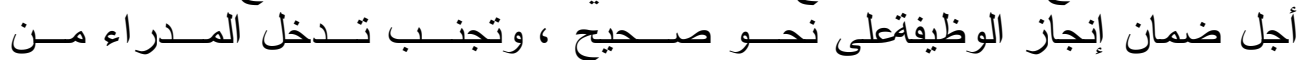

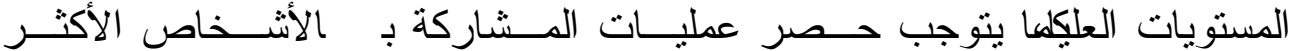

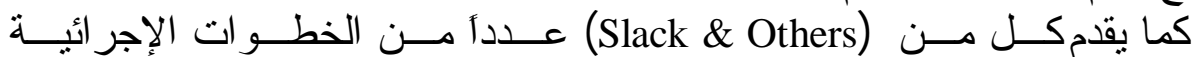

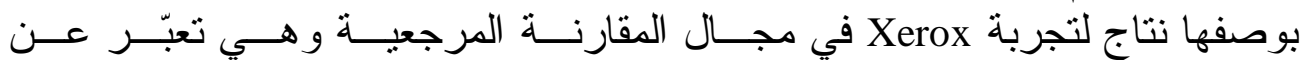

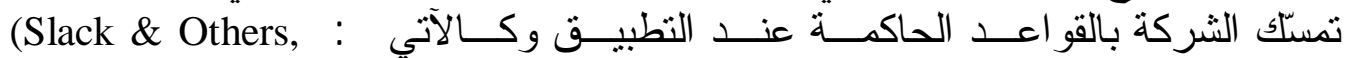
2004, 645)

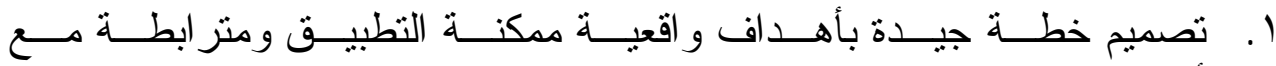

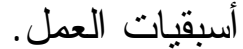

r. معرفة المعلومات المرتبطـــة بمسـتوى أداء العمليــات الحاليــة و إيــصالها

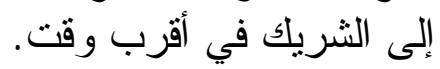

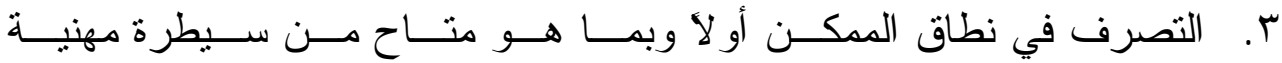
وصدق ولطف ويقظة.

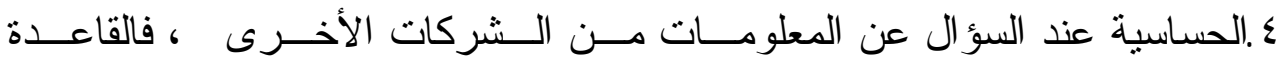

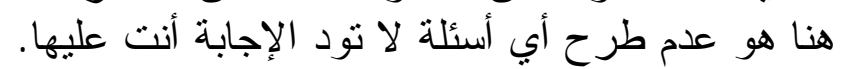

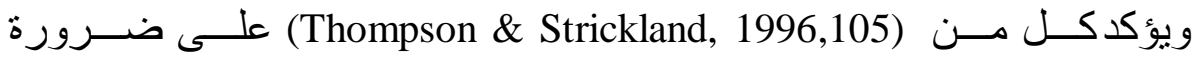

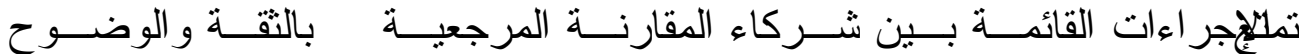

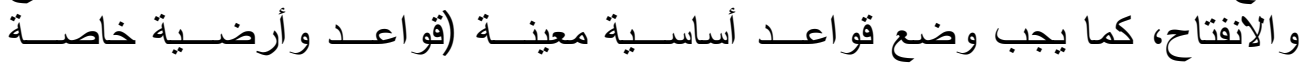

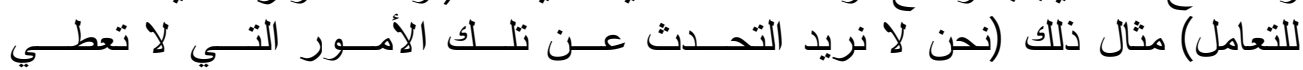

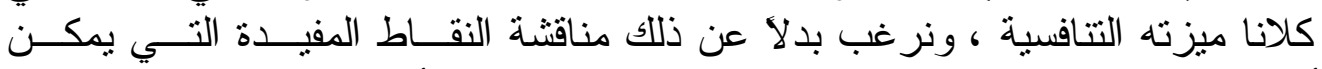

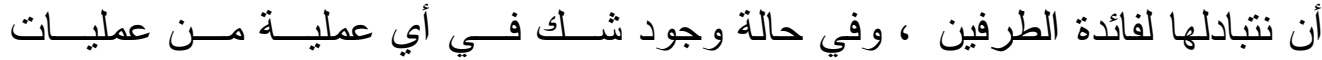

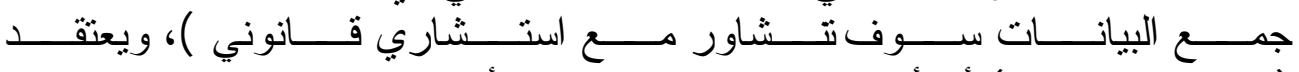
(William,2005,72)

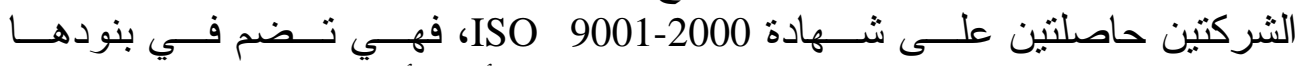

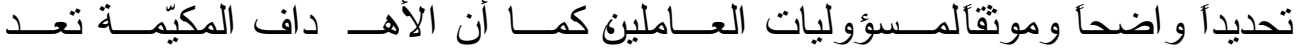

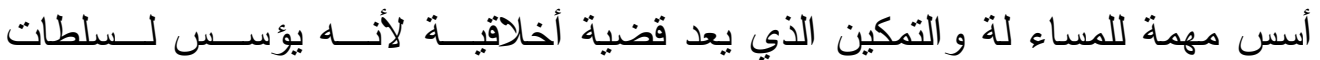
العاملين طبقأ لجهودهم، وهو يؤثر في جودة قرار التهر التهم. 
رابعاً - الخلاصة

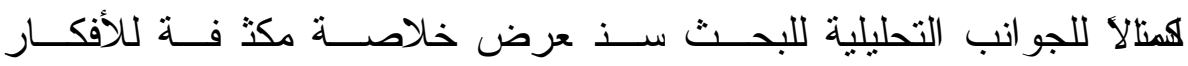

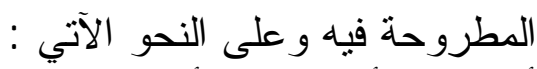

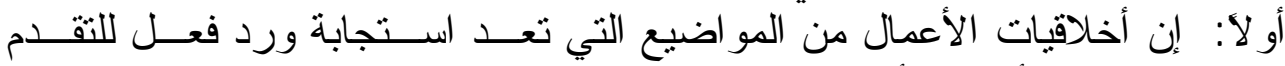

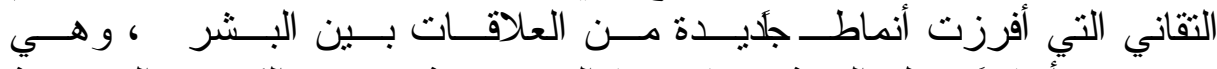

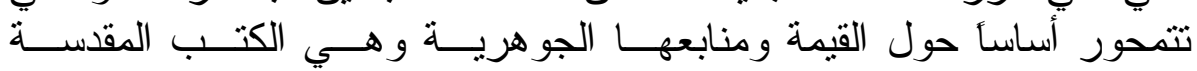

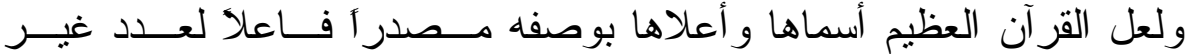

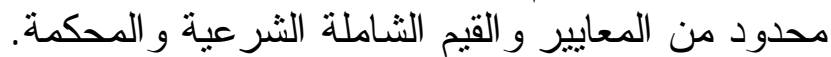

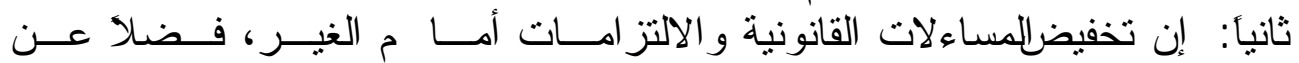

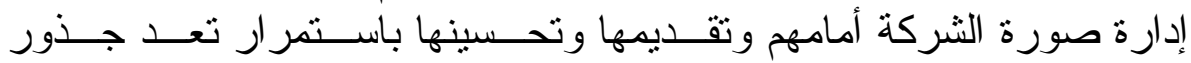

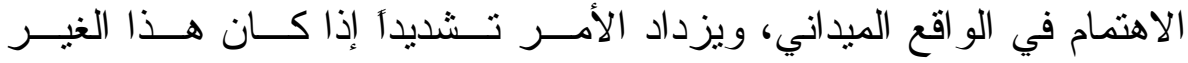

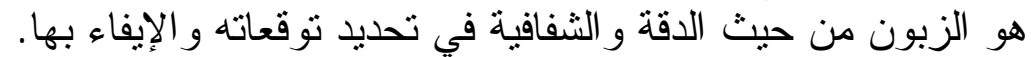

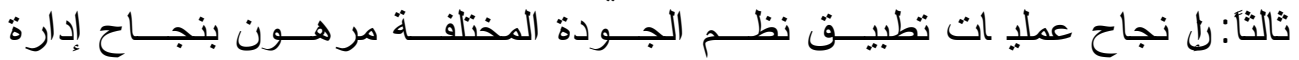

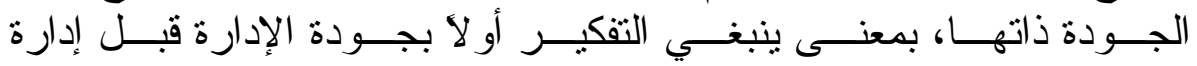

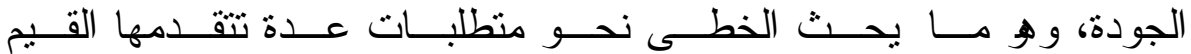
الأخلاقية التي ستغدو قيم الشركة ككل.

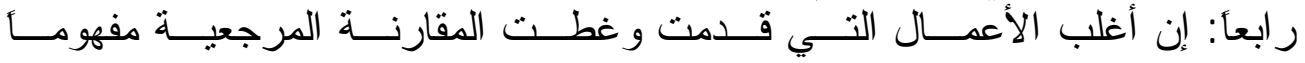

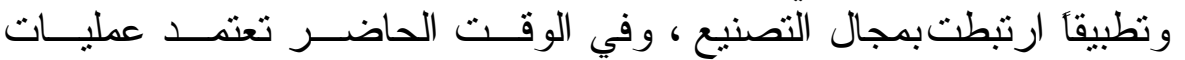

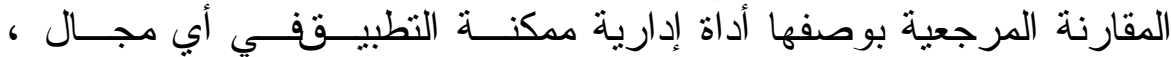

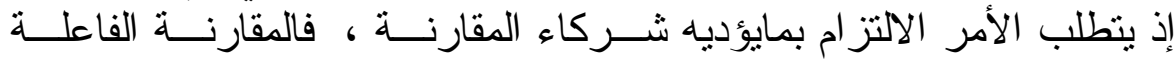

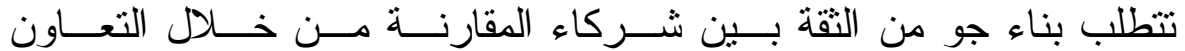
و التعلم فيما بينهم.

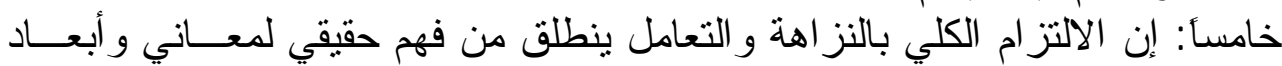

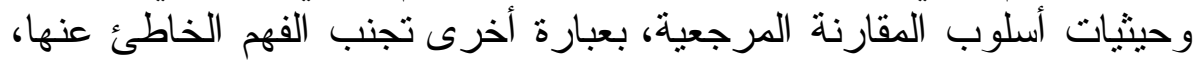

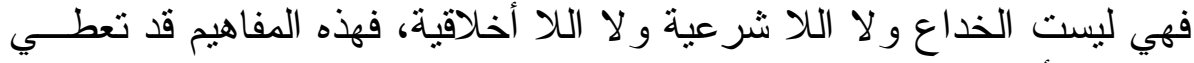

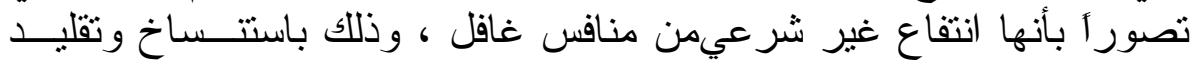

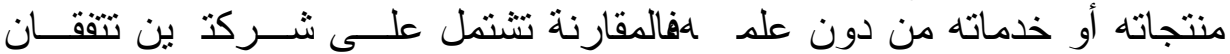

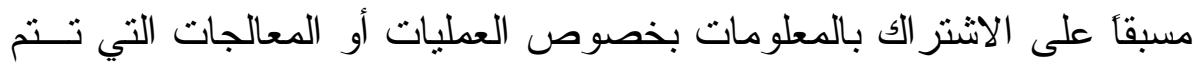
فيها، وكلتا الثركتين تتوقعان مسبقاً حصولهما على منافع من هــــا التبــادل

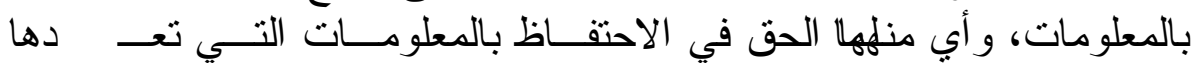
خاصة.

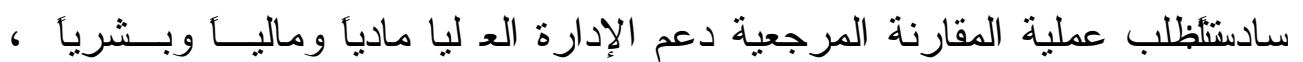

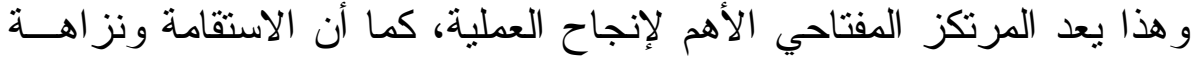

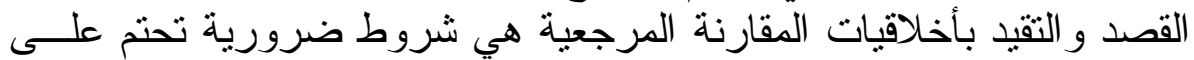

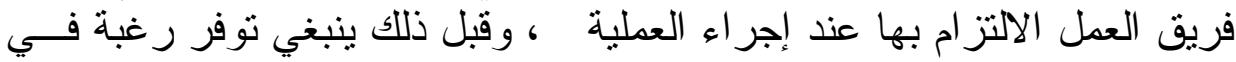


تقبل الحقائق غير الـ جيدة عن أداء الشركة عند تشخيص مقدار الفجــوة التــي

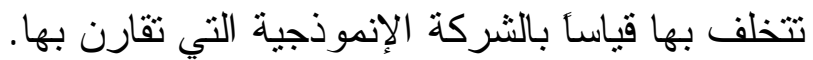

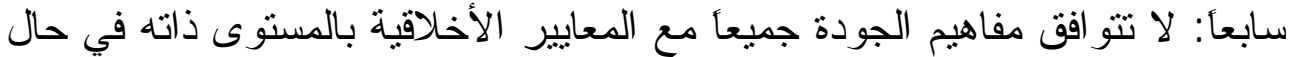

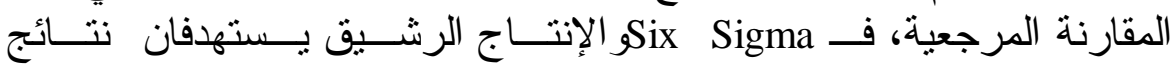

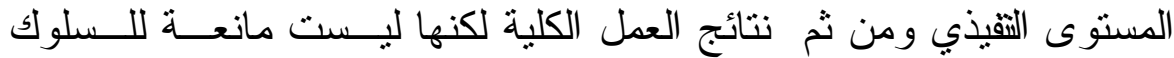

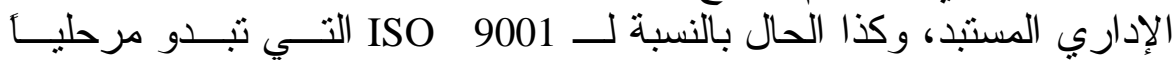

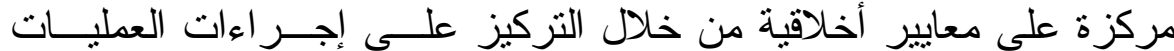

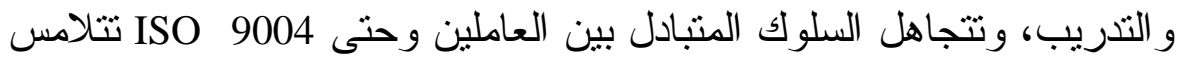

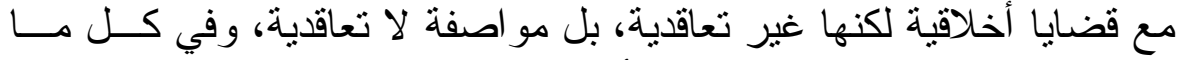

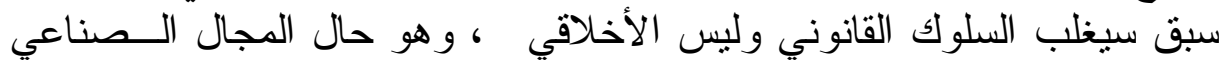

\section{المر اجع المر اجع باللغة العربية}

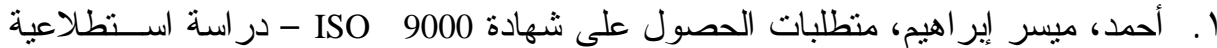

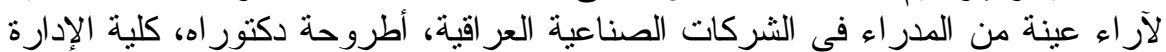

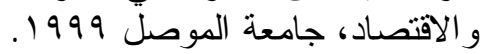

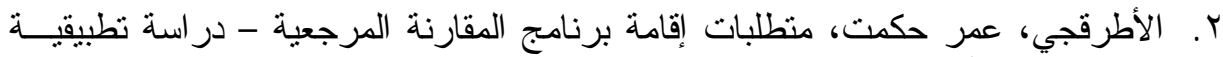

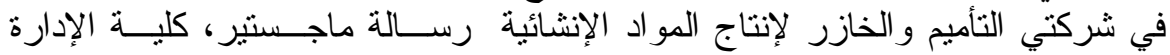

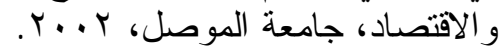

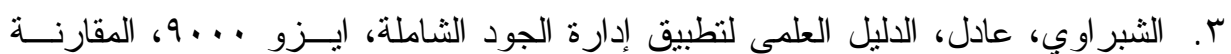

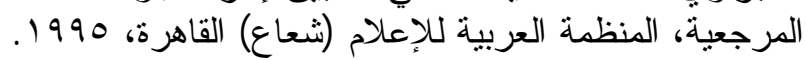

\section{ثانياً - المر اجع باللغة الأجنبية}

1. Belinda ,Barkhuysen, \& Gedeon J, Rossouw , "Business ethics as academic Field in Africa:its Current Status "A European Review,Vol. 9,No.4, 2000.

2. British Standards Institute (BSI), BS 5750-1987, BSI.

3. Camp, Robert "Bench marking: The search for best practices that lead to superior performance "Quality progress, march, 1989.

4. Dilworth, Dilworth, James B, "Operations Management ", 3rd ed., McGraw - Hill,New York.,1996.

5. Enslen, Peter, M.,'Benchmarking Canadian Public Works Association. Pdf/ Benchmarking, pdf 2000.

6. Evans, A. " Avoid these Ten Bench Marking Mistakes, www.benchmarking Plus .com. au./mistakes.htm. 2006.

7. Feigenbaum , A. V. “Quality \& Business Growth Today “ Quality Progress , Nov. ,1982.

8. Finance-Benchmarking, FAQ, 2001, Benchmarking, Ethics, http:11 www. Finance, gov.au/benchmark/benchmarking ethics. htm/ .

9. Freund , R.A. “Quality Technology - A Bridge To International Cooperation " Quality Progress , Feb, 1980 .

10. Greenwood ,Michelle R, "The Study of Business Ethics : A case For Dr Seuss " , A European Review, Vol.9 ,No.3 ., 2000. 
11. Irwin ,Richard” Benchmarking \& Ethics, WWW.Csuchico /edu /mgmt /strategy. 1995.

12. John, Reh " Benchmarking : Who's Best, How Good Are They, How Do We Get That Good http :// management .about .com/ cs /benchmarking/a/Benchmarking.htm 2006.

13. Kenneth ,C. L. \& Jane , P. L. 2006 " Management Information Systems ", Pearson Prentice Hall. , .

14. Krajwiski ,L .J.\& Ritzman ,K.P.”Operations Management-Processes \& Value Chains " $7^{\text {th }}$.ed. ,Prentice Hall ,Inc. 2005.

15. Leandri, Suson, J "Two Essential Tools for the New Internal Auditor. Bench making and Best Practices, http://www. And ersen .com/resource.Z. nsf/Vattachlu/Essential to olsinternal /Anditor GBP/ \$ Fr/elst R27 28. pdf. .2000.

16. Marnburg , Einar, "The Behavioural Effects of Corporate Ethical Codes : Empirical Findings \& Discussion ", A European Review , Vol.9 ,No.3 2000.

17. Murray, T. J. " Meeting The New Quality Challenge " Research Management, Nov.Dec. 1987.

18. Parry , Mathew H. "Code of Etgics for Project Managers ", Project Management Quarterly, Vol.3, No.4, 1980 .

19. Russell, Robert, S. \& Taylor 111, Bernard, W." Production and Operations Management focusing on Quality and Competitiveness " prentice-Hall, Inc, Englewood Cliffs 1995.

20. Schermerhorn , John R., "Management for Productivity ", John Wiley \& Sons Inc., New York, 1996.

21. Slack, Nigel, chambers ,S. \& Johnston, R. "Operation Management " Prentice Hall, Essex , UK, 2004.

22. Thompson, Arthur, A., Jr., \& Strickland II., A., J.” Strategic Management. Concepts \& Cases" 9th .ed. Irwin McGraw-Hill, 1996.

23. William, A. S. " A Deming Inspired Management Code Of Ethics " Quality Progress, Feb2005.

24. www. Igba.org. ethical. essues .fedral ,state , jan.2007. 